UNIVERSITY OF NOTTINGHAM

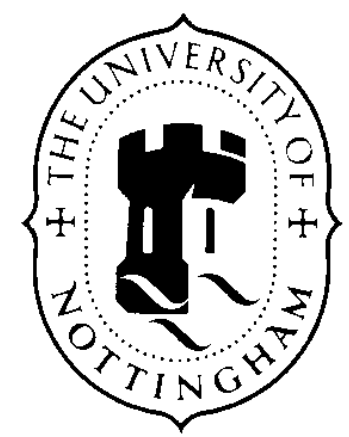

Discussion Papers in Economics

\title{
Money and Information in a New Neoclassical Synthesis Framework
}

\author{
Philip Arestis \\ Georgios Chortareas \\ John D. Tsoukalas
}

January 2010 


\title{
Money and Information in a New Neoclassical Synthesis Framework
}

\author{
Philip Arestis \\ University of Cambridge
}

\author{
Georgios Chortareas \\ University of Athens \\ University of Essex
}

\author{
John D. Tsoukalas* \\ University of Nottingham
}

Revised: May 2009

\begin{abstract}
We consider an (otherwise standard) New Neoclassical Synthesis theoretical framework that allows a role for money. Money in our model has an informational role which consists in facilitating the estimation of the unobserved shocks that drive potential output and thus the state of the economy. For this purpose we estimate a small-scale sticky price model using Bayesian techniques. Our findings support the view that money has information value. This is reflected in higher precision in terms of unobserved model concepts such as the natural rate of output. Moreover, our results highlight how modelling money demand can provide insights about structural features of the economy that may be important for the design of interest rate rules. Focusing on money also allows for a step towards resolving the price puzzle. Money demand shocks can confound monetary policy shocks to generate a perverse price response in vector autoregressions (VAR).
\end{abstract}

JEL classification: D58, E31, E32, E52.

Key words: DSGE models; New Keynesian models; Money; Monetary Policy; Bayesian analysis.

* Corresponding author: john.tsoukalas@ nottingham.ac.uk. We thank two anonymous referees for helpful suggestions and comments that improved the paper. We also like to thank Kostas Katirtzidis for excellent research assistance. 


\section{Introduction}

Conventional wisdom renders money redundant in the current consensus business cycle models used for policy analysis. The New Keynesian (or New Neoclassical Synthesis -NNS) model with sticky prices has become the standard workhorse for monetary policy analysis in the last fifteen years or so (see Rotemberg and Woodford (1997), Goodfriend and King (1997), Galí (2003)). This model has been used to address a number of questions, ranging from the interpretation of monetary business cycle stylised facts to evaluating and designing monetary policy. In this model the policy instrument is the short-term (nominal) interest rate and money plays no role, typically resulting to a dismissal of any reference to monetary aggregates. There exist aspects of monetary policy design in practice, however, that do not reconcile easily with the above description. As Bernanke (2006) observes “..... the Federal Reserve will continue to monitor and analyze the behavior of money. Although a heavy reliance on monetary aggregates as a guide to policy would seem to be unwise in the U.S. context, money growth may still contain important information about future economic developments." Moreover, while the European Central Bank (ECB) embraces the NNS, one of the two pillars on which its monetary policy is based on, assigns a "prominent" role for money (following Bundesbank's tradition). In the context of the academic debate one can also encounter concerns about the easiness with which money is dismissed (e.g., Lucas (2007); Friedman (2003); Goodhart (2007)). While the possibility of a role for money is recognized, no clear consensus exists as to how it should be incorporated in a framework useful for policy analysis. Consequently, the challenge of pinning down the channel through which money's role is materialized emerges. There exist some recent attempts to resuscitate money's role in NNS models without challenging the role of interest rates as the main policy instrument. In such models money does not have direct effects but facilitates inferences about the state of the economy (e.g., Andrés et al. (2009), Beck and Wieland (2007), Nelson (2002)). This paper develops a model in this spirit where money plays a non-trivial role. Our framework is a typical New Keynesian business cycle model with the nominal interest rate as the main policy instrument. Nevertheless introducing money explicitly allows producing important insights about the natural rate of output as compared to the standard moneyless consensus model.

We develop a small-scale sticky price model that includes money in a non-trivial way and focus on two set of issues that have important consequences for the conduct and transmission mechanism of monetary policy. First, we show that money can convey information about the state of the economy. To accurately assess the state of the economy requires precise information about the size and the nature of shocks hitting it. We establish the informational value of money by estimating a small scale structural sticky price model and show that the potential output estimate improves considerably in terms of precision as compared to a conventional sticky price model—with no role for money. The importance of more accurate information regarding the output gap is more profound in the context of inflation targeting where monetary policy becomes "an economists job". Second, we examine whether adding money in such a model has implications about the way we understand the structural features of the economy. To demonstrate this point in a simple way we focus on the fraction of rule-of-thumb consumers which proves important for the conduct of monetary policy as analysed in Amato and Laubach (2003) and Galí et al. (2004). These authors demonstrate that the presence of rule-of-thumb households is not inconsequential, since it calls for different policy prescriptions regarding the design 
of monetary policy rules in a standard otherwise sticky price model. Thus, from a policy perspective, it becomes important to accurately quantify the importance of rule of thumb behaviour in the context of an estimated New Keynesian model. Indeed we find that the estimates about the fraction of rule-of-thumb differ considerably depending on the assumptions used to model money demand; and this is so whether or not money is used in the estimation procedure, thereby highlighting another dimension that money may help shed light on. Other structural parameters differ to a smaller degree. It is important to stress that this role for money arises over and above any information contained in output, inflation and the nominal interest rate.

To formally assess the validity of the above hypothesis regarding the usefulness of money we use US data from 1959 II to 2007 IV to estimate a (canonical) version of the model with rule-of-thumb consumers as in Amato and Laubach (2003). We estimate a version where money is absent (or has a trivial role), and a version that embeds a money market with a forward-looking money demand. A monetary policy is also included, which responds both to conventional variables ala Taylor and to nominal money growth in line with existing evidence. Our estimation results suggest that the data strongly support a version of the model that incorporates a forward-looking money demand and money in the policy rule. We conclude that money may convey useful information for features of the economy that are crucial for understanding the transmission of shocks and the design of monetary policy rules. Our results corroborate the findings of Boivin and Giannoni (2006) that call for use of a wide range of indicators, including monetary aggregates, in recently developed estimated dynamic stochastic general equilibrium (DSGE) models.

We then use our model to shed light on two related puzzles appearing in the empirical literature that identifies the effects of monetary policy shocks. The first is the liquidity puzzle, which refers to the finding that nominal interest rates are positively associated with the money stock (or money growth). The second is the so-called price puzzle, which emerges when the price level rises (at least for some time) following a tightening of policy. Recently Leeper and Roush (2003) using empirical vector autoregressive (VAR) methods on US data find that the price and liquidity puzzles largely disappear once a monetary aggregate is among the set of variables in vector auto-regressions that seek to identify monetary policy shocks. We use our model as a laboratory to examine impulse response functions of key macroeconomic variables following monetary policy and money demand shocks. In our exercise the price puzzle emerges because money demand shocks contaminate monetary policy shocks. Our analysis corroborates the findings in Leeper and Roush (2003). Money demand and monetary policy shocks produce very similar responses in terms of nominal and real interest rates and the response of real variables such as output. However, they are associated with opposite movements of inflation and the price level. Thus recursive identification schemes that ignore the intricacies of money demand and the role of monetary aggregates in the conduct of monetary policy may have a hard time properly separating monetary policy from money demand shocks.

The rest of the paper is structured as follows. The following section provides a brief discussion of existing studies focusing on money in the context of NNS models. Section 3 describes the model set-up, Section 4 presents the estimation methodology and results and section 5 concludes. 


\section{Literature Review}

Money is an intrinsic part of the literature on monetary policy. Its role has been investigated extensively and from many angles. At the same time money is absent from the standard NNS models used for policy analysis. A number of attempts to introduce money in a direct way exist but the empirical evidence is not very encouraging for this avenue of investigation. For example, Ireland (2004) and Andrés et al. (2006) explore the non-separability channel between consumption and real money balances in the US and the Euro area respectively. Neither, however, uncovers strong evidence favouring such a relationship.

The presence of money in NNS models can be introduced and justified in more subtle ways. Nevertheless, all such attempts share the common feature that money contains information well and above that existing in the standard NNS model. This information pertains to latent variables such as the natural rate of output or the natural equilibrium real interest rate. Differences exist between models, however, regarding the channels through which information is uncovered and disseminated. The informational channel as a vehicle for uncovering the role of money in otherwise standard models of NNS has been introduced by Nelson (2002) and further developed and empirically estimated for the US and the Euro area by Andrés et al. (2009). These contributions focus on the implications of money for the natural interest rate and provide evidence in support of money's role as an indicator of future variations in that rate. They use three model specifications, one with separable utility and static money demand, one with nonseparable utility and internal habit formation, and one with portfolio adjustment costs for real money balances holdings.

A second direction for extracting information from money is to use the long-term properties of monetary aggregates to mitigate problems arising from the presence of mis-perceptions. This is the 'cross-checking' principle as suggested by Lucas (2007). Beck and Wieland (2007) provide a characterisation of the cross-checking principle in the context of the ECB's policy. Mis-perceptions may arise regarding either the equilibrium level of output or the real interest rate. In this paper the central bank checks regularly whether money growth, after adjusting for output and velocity trends, is consistent with the inflation target or deviates from it. The central bank may adjust the interest rate in response to signals of repeated and sustained deviations from the target.

Finally a more empirically oriented study by Coenen et al. (2005) focuses on money's role as an indicator variable when revisions to data take place. The authors find that there is a potentially significant role for monetary aggregates, which is the precision of information about current real output. The information content of monetary aggregates about the true state of the economy is important when the variability of output measurement errors is high. In contrast, high variability of money demand shocks impairs that role of money.

While our model has similarities and borrows elements from the above-mentioned contributions it has some distinct features. First, we focus on the role of money in revealing information about the natural rate of output and the output gap but also for structural features of the economy that may be important for the conduct of monetary policy. ${ }^{1}$ Second, we distinguish the implications of the portfolio adjustment costs assumption from those emerging due to the habit formation assumption. This

\footnotetext{
${ }^{1}$ Of course characterising the natural rate of output implies a characterisation for the natural rate of interest.
} 
approach complements that of Andrés et al. (2009) and our results corroborate their findings. Moreover we attempt to make a broader point since the existing models typically focus on a limited number of structural parameters while the framework adopted in the present paper permits consideration of a wider set of structural parameters.

The assumption of portfolio-adjustment costs renders monetary aggregates more forward-looking but does not make them special in the sense implied by the ECB's two pillar strategy. In the ECB's framework money acts as a cross check on the economic analysis and the focus is on the medium to long run. Money's role is independent to the model being used for the short run economic analysis. By contrast, in our model money's role emerges when considered jointly with the other variables. The optimal forecast is based on a joint assessment of all relevant variables conditional on the structure of the model. ${ }^{2}$

Finally, the estimates we provide are based on Bayesian techniques and this differentiates further our work from the aforementioned literature. For example, Andrés et al. (2009) conduct their estimations using classical maximum likelihood methods. Bayesian estimation, however, is quickly becoming the dominant methodology for the empirical assessment of DSGE models in many central banks. When the task at hand involves estimating a large number of structural parameters from a DSGE model, the classical econometric framework acts as a straightjacket restricting the number of parameters for which we can gain information. The ability of Bayesian models to provide a rich structural framework is particularly valuable for obtaining accurate forecasts about the state of the economy. The relevance of this is more profound for central banks engaging in explicit inflation forecast targeting. Finally, we broaden our focus by considering the implications of money for the price and liquidity puzzles.

\section{The Model}

We use a small structural sticky price model based on Amato and Laubach (2003) where households are both producers and consumers of a continuum of differentiated products. We extend this framework to incorporate a non-trivial role for money. Households can behave optimally or according to a rule-of-thumb with respect to consumption choices. Rule-of-thumb behaviour in consumption may arise because of optimisation/cognitive costs, or relatedly because of limited capability of households to process large flows of information (e.g., Sims (2003), Gabaix and Laibson (2001), Gabaix and Laibson (2005)). In addition to consumption behavior we allow for rule-of-thumb behavior with respect to holdings of money balances. A consistent treatment of agents' behavior requires imposing the same behavioural assumptions on consumption and financial (money demand) choices. The rule-of-thumb behaviour regarding portfolio choices (relative bond and money holdings) can be supported by the presence of adjustment or transaction costs in household portfolios (Guiso et al. (2002), Haliassos and Michaelides (2002)).

\subsection{Demand Side}

\subsubsection{Consumers-producers}

There is a continuum of ex-ante identical households indexed by $i, i \in[0,1]$. Each household $i$ is a consumer and supplier of a differentiated product. In each period a household learns whether s/he is able to choose consumption and real money balances

\footnotetext{
${ }^{2}$ We thank an anonymous referee for bringing this point to our attention.
} 
optimally or using a rule of thumb. The probability that the household is able to optimise is denoted by $\psi$ and is independent of the household's history. ${ }^{3}$ Consequently, by the law of large numbers in any given period the fraction of households that are able to optimise (denoted by a superscript $o$ ) is given by $\psi$ while the fraction of households that use a rule of thumb (denoted by superscript $n o$ ) is given by $1-\psi$. The fraction of households that are unable to optimise set their consumption according to the rule-of-thumb $C_{t}^{n o}=C_{t-1}$. We define a similar rule-of-thumb for money balances shortly.

Thus, the household's objective is to maximise

$$
E_{0} \sum_{t=0}^{\infty} \beta^{t}\left[\psi u\left(C_{t}^{i}, \frac{M_{t}^{i}}{P_{t}}, \frac{M_{t-1}^{i}}{P_{t-1}} ; g_{t}, w_{t}\right)+(1-\psi) u\left(C_{t}^{n o}, \frac{M_{t}^{n o}}{P_{t}}, \frac{M_{t-1}^{n o}}{P_{t-1}} ; g_{t}, w_{t}\right)+v\left(y_{t}^{i} ; z_{t}\right)\right]
$$

where $\beta$ is a discount factor, $y_{t}^{i}$ is the output of the good produced by household $i, C_{t}^{i}=\left[\int_{0}^{1} c_{t}^{i}(z)^{\frac{\theta-1}{\theta}} d z\right]^{\frac{\theta}{\theta-1}}$, is the usual Dixit-Stiglitz aggregate of the continuum of goods purchased by the household, $\frac{M_{t}^{i}}{P_{t}}$ denotes real money balances and $g_{t}, w_{t}, z_{t}$ are disturbances to be defined momentarily. The household views $C_{t}^{n o}$ as exogenous and maximises (3.1) with respect to $C_{t}^{i}$ subject to a budget and a demand constraint. As a producer the household faces the following demand curve, $y_{t}^{i}=\left(\frac{P_{t}^{i}}{P_{t}}\right)^{-\theta} Y_{t}$, where $\theta>1$ denotes the elasticity of demand for each differentiated product $i$ which is identical to the elasticity of substitution in the consumption index above.

The household's budget constraint is given by,

$$
P_{t} C_{t}^{i}+\frac{B_{t}^{i}}{R_{t}}+M_{t}^{i}=B_{t-1}^{i}+M_{t-1}^{i}+P_{t} Y_{t}+T_{t}
$$

where $Y_{t}$ is aggregate output, and $P_{t}$ the aggregate price index corresponding to the aggregate consumption $C_{t}$. $B_{t}$ denotes nominal riskless one period bonds and $R_{t}$ is the gross nominal interest rate. We assume complete financial markets such that households have perfect insurance opportunities against all idiosyncratic risk, either the risk arising from the dispersion of prices and/or the risk associated from not being able to choose their consumption optimally. This allows us to write a single intertemporal budget constraint. Moreover, $T_{t}$ denotes exogenous (as viewed by the households) transfers that offset the wealth effects that may arise because of the different choices between optimising and rule of thumb households.

The functions $u(), v()$ in (3.1) are specified as follows.

$$
u\left(C_{t}^{i}, \frac{M_{t}^{i}}{P_{t}}, \frac{M_{t-1}^{i}}{P_{t-1}}\right)=g_{t} \frac{1}{1-\sigma}\left(C_{t}^{i}-H_{t}\right)^{1-\sigma}+w_{t} \frac{1}{1-\gamma}\left(\frac{M_{t}^{i}}{P_{t}}\right)^{1-\gamma}-\Phi\left(\frac{M_{t}^{i}}{P_{t}}, \frac{M_{t-1}^{i}}{P_{t-1}}\right)
$$

where the parameters $\sigma>0$, is the inverse elasticity of intertemporal substitution relative to the external habit, $H_{t}=h C_{t-1}$ and $\gamma>0$ is related to the inverse elasticity of real money balances with respect to the (nominal) interest rate. The function $\Phi(\bullet)$ captures portfolio adjustment (or management) costs as in Christiano and Eichenbaum (1992) and Nelson (2002) and is given by,

$$
\Phi\left(\frac{M_{t}}{P_{t}}, \frac{M_{t-1}}{P_{t-1}}\right)=d\left[\exp \left(c\left(\frac{\frac{M_{t}}{P_{t}}}{\frac{M_{t-1}}{P_{t-1}}}-1\right)\right)+\exp \left(-c\left(\frac{\frac{M_{t}}{P_{t}}}{\frac{M_{t-1}}{P_{t-1}}}-1\right)\right)-2\right]
$$

\footnotetext{
${ }^{3}$ This formulation is analogous to the Calvo (1983) assumption on price setting.
} 
where $c, d \geq 0$. In what follows we adopt the normalisation $c=1$. Modelling habit formation as external implies that the forward-looking nature of money demand is solely attributable to portfolio adjustment costs. Finally, $v\left(y_{t}\right)=z_{t} \frac{1}{1+\lambda} y_{t}^{1+\lambda}$, where $\lambda>0$ denotes the inverse labour supply elasticity. ${ }^{4}$ The preference, $g_{t}$, money demand, $w_{t}$, and supply shocks, $z_{t}$ follow first order autoregressive processes: $\ln g_{t}=\left(1-\rho_{g}\right) \ln g+\rho_{g} \ln g_{t-1}+\varepsilon_{g t}, \ln w_{t}=\left(1-\rho_{w}\right) \ln w+\rho_{w} \ln w_{t-1}+\varepsilon_{w t}$, $\ln z_{t}=\left(1-\rho_{z}\right) \ln z+\rho_{z} \ln z_{t-1}+\varepsilon_{z t}$, where $g, w, z>0$ and the zero mean, serially uncorrelated innovations, $\varepsilon_{g t}, \varepsilon_{w t}, \varepsilon_{z t}$ are iid normally distributed with standard deviation, $\sigma_{g}, \sigma_{w}, \sigma_{z}$ respectively.

The consumption of households that have the opportunity to optimise is denoted by $C_{t}^{o}$, whereas that of the rule of thumb households is given by $C_{t}^{n o}$. Total consumption is then given by $C_{t}=\psi C_{t}^{o}+(1-\psi) C_{t}^{n o}$. Since there is no capital in this economy, market clearing in the goods market requires, $C_{t}=Y_{t}$.

CONSUMPTION. Log-linearising the consumption Euler equation-using lower case letters to denote log deviations from steady state values-yields the IS curve that describes the demand side of the model (described in Appendix 1)

$$
x_{t}=\left(h+\psi^{-1}(1-\psi)\right) \delta^{-1} x_{t-1}+\delta^{-1} \psi^{-1} E_{t} x_{t+1}-\sigma^{-1}(1-h) \delta^{-1} E_{t}\left[r_{t}-r r_{t}^{n}-\pi_{t+1}\right]
$$

where $x_{t}=y_{t}-y_{t}^{n}$ denotes the output gap, defined as the deviation of actual output from its natural rate (i.e. the one would obtain if all prices were fully flexible). The composite parameter $\delta$ is defined as $\delta=h+\psi^{-1}(2-\psi)$ and $r r_{t}^{n}$ denotes the natural rate of interest, defined as

$$
r r_{t}^{n}=\sigma(1-h)^{-1} \delta\left[\delta^{-1} \psi^{-1} E_{t} y_{t+1}^{n}+\left(h+\psi^{-1}(1-\psi)\right) \delta^{-1} y_{t-1}^{n}-y_{t}^{n}-\sigma^{-1}(1-h) \delta^{-1}\left(g_{t+1}-g_{t}\right)\right]
$$

MONEY DEMAND. Combining the optimising households' optimality condition (derived in Appendix 1) along with the rule of thumb $m_{t}^{n o}=m_{t-1}$ for those households not able to optimise, yields the following log-linearised money demand equation:

$$
\begin{gathered}
-\left(\mathcal{A}_{0}+\beta \mathcal{A}_{1}(1-\psi)\right) m_{t}+\left(\mathcal{A}_{1}+\mathcal{A}_{0}(1-\psi)\right) m_{t-1}-\left(\mathcal{A}_{1}(1-\psi)\right) m_{t-2}+\sigma(1-h)^{-1}\left(y_{t}-\psi\left(h+\psi^{-1}(1-\psi)\right) y_{t-1}\right) \\
+\beta \mathcal{A}_{1} E_{t} m_{t+1}-\frac{\psi}{\bar{r}-1} r_{t}+\psi w_{t}=0
\end{gathered}
$$

where $m_{t}$ denotes real money balances, while $\mathcal{A}_{0}=\left[\gamma+\frac{2 d c^{2} \bar{C}^{\sigma} \bar{r}(1-h)^{\sigma}}{\bar{m}(\bar{r}-1)}(1+\beta)\right]$, and $\mathcal{A}_{1}=\left[\frac{2 d c^{2} \bar{C}^{\sigma}(1-h)^{\sigma} \bar{r}}{\bar{m}(\bar{r}-1)}\right]$ are positive parameters.

We assume that the fraction of households not able to optimise follow a rule analogous to the one followed for consumption, i.e. simply maintaining last period's real money balances. This can be a realistic assumption if one consider that with many assets and rates of returns (and possibly transaction costs) it is difficult/impossible for the average household that holds positive assets to re-optimise (switch between money and bonds) its portfolio continuously (e.g., Guiso et al. (2002), Haliassos and Michaelides

\footnotetext{
${ }^{4} \mathrm{We}$ assume that the underlying production function is given by $y_{t}=A_{t} h_{t}$ and interpret $z_{t}$ as a composite supply shock consisting of a labour supply and the technology shock $A_{t}$. A similar simplification is adopted in Rotemberg and Woodford (1997).
} 
(2002), Vissing-Jørgensen (2002), Luttmer (1999)). Moreover, the rule-of-thumb assumption is attractive because the imposition of adjustment costs makes households more willing to keep a smooth profile of money balances. For example, Luttmer (1999) studies the effect of adjustment costs on optimal cash holdings. Vissing-Jørgensen (2002) provides an empirical assessment of the various forms of portfolio adjustment costs.

Note that the portfolio adjustment cost formulation makes money demand forward looking. This is reflected in the $E_{t} m_{t+1}$ term. It is also useful to note that this money demand function nests the standard static money demand (setting $d=0)$. In this case equation 3.4 reduces to,

$$
-\gamma m_{t}+\gamma(1-\psi) m_{t-1}+\sigma(1-h)^{-1}\left(y_{t}-\psi\left(h+\psi^{-1}(1-\psi)\right) y_{t-1}\right)-\frac{\psi}{\bar{r}-1} r_{t}+\psi w_{t}=0
$$

More importantly this forward looking specification implies that current real money balances depend both on lagged real balances and expectations of future real interest rates, inflation and output. Thus money may contain useful information about future developments in aggregate demand which in theory depends on current and future expected real interest rates. ${ }^{5}$ In fact in section 3.1.3 we show that money can contain information about the structural shocks of the model—in particular preference and supply shocks - and in section 4 we present estimates that indicate the usefulness of money in constructing more precise estimates of the model's unobserved variables.

The fact that real money balances may convey information about the structural shocks that drive movements in output, inflation and the nominal interest rate implies that it may also contain useful information for the presence of optimising vs. rule of thumb consumers as well as the other structural parameters of the model. To the extent that money contains additional information about the unobserved components of the model, i.e. various structural shocks, implies that unobserved model concepts are better measured, which in turn should imply that estimation becomes more efficient. This point is nicely illustrated in Boivin and Giannoni (2006). We elaborate and quantify as necessary, on this point in the estimation section of the paper.

\subsubsection{Price setting}

We follow the Calvo (1983) tradition and assume that only a fraction $(1-\xi)$ of suppliers are able to reset their price in each period. The remaining fraction of suppliers $\xi$, is required to maintain their prices. The maximization problem facing a supplier that is offered the opportunity to change its price at time $t$ is given by,

$$
\max _{\left\{P_{t}^{i}\right\}} E_{t} \sum_{j=0}^{\infty}(\xi \beta)^{j}\left[\frac{P_{t}^{i}}{P_{t+j}} u_{c}\left(Y_{t+j} ; g_{t+j}\right)\left(\frac{P_{t}^{i}}{P_{t+j}}\right)^{-\theta} Y_{t+j}-v\left(\left(\frac{P_{t}^{i}}{P_{t+j}}\right)^{-\theta} Y_{t+j} ; z_{t+j}\right)\right]
$$

Solving (3.6) by choice of $P_{t}^{i}$ yields the familiar 'New-Keynesian Phillips curve' that relates current inflation rate to the output gap and expectations of the future inflation rate. ${ }^{6}$ We, then have

\footnotetext{
${ }^{5}$ Indeed, Nelson (2002) shows that (various) measures of real money growth have significant explanatory power for cyclical output in the US after controlling for measures of real short term rates. Moreover, and in related work, Andrés et al. (2009) build on this insight and show that money balances contain information for the natural rate of interest.

${ }^{6}$ In deriving the Phillips curve we assume that all consumers are able to choose consumption optimally, so that the marginal utility of consumption is identical across them. To conserve space we omit the full derivation of the Phillips curve. The derivation details can be found
} 


$$
\pi_{t}=\beta E_{t}\left(\pi_{t+1}\right)+\phi\left[\left(\lambda+\sigma(1-h)^{-1}\right) x_{t}-\sigma h(1-h)^{-1} x_{t-1}\right]
$$

where $\phi=\frac{(1-\xi \beta)(1-\xi)}{\xi(1+\lambda \theta)}$, and the natural rate of output is given by,

$$
y_{t}^{n}=-z_{t}+g_{t}+\frac{\sigma h(1-h)^{-1}}{\left(\lambda+\sigma(1-h)^{-1}\right)} y_{t-1}^{n}
$$

\subsubsection{The information role of money}

A key insight we wish to clarify is whether variation in real money balances conveys anything about the unobserved concepts of the model. We focus in particular on the natural rate of output. Equation (3.8) shows that the variation in the natural rate of output is driven by supply and preference shocks. We begin with the observation-implicit in the canonical sticky price model— that with a static money demand function all information about the natural rate of output is already contained in output and the nominal interest rate. In that model real money balances can be solved recursively from the other equations that summarize the demand and supply side as well as the behaviour of the central bank. Therefore, given the presence of money demand shocks the information content of money is reduced, since variation in real money balances conditional on output and the nominal interest rate simply reflects noise.

To illustrate the information content of money with as much simple algebra as possible we momentarily drop the rule-ofthumb and habit persistence assumptions (i.e. we set $\psi=1$ and $h=0$ ). In this case the money demand equation (3.4) can be written as,

$$
-\mathcal{A}_{0} m_{t}+\mathcal{A}_{1} m_{t-1}+\sigma y_{t}+\beta \mathcal{A}_{1} E_{t} m_{t+1}-\frac{1}{\bar{r}-1} r_{t}+w_{t}=0
$$

or equivalently,

$$
m_{t}=\eta_{0} m_{t-1}+\eta_{1} y_{t}+\eta_{2} E_{t} m_{t+1}+\eta_{3} r_{t}+\eta_{4} w_{t}
$$

where $\eta_{0}=\frac{\mathcal{A}_{1}}{\mathcal{A}_{0}}, \eta_{1}=\frac{\sigma}{\mathcal{A}_{0}}, \eta_{2}=\frac{\beta \mathcal{A}_{1}}{\mathcal{A}_{0}}, \eta_{3}=-\frac{1}{\mathcal{A}_{0}(\bar{r}-1)}, \eta_{4}=\frac{1}{\mathcal{A}_{0}}$. In Appendix 1 we show that we can express equation $(3.9)$ above as,

$$
\begin{gathered}
m_{t}=\mu_{1} m_{t-1}+\delta_{0} y_{t}+\tau_{0} r_{t}+\zeta_{0} w_{t}+\left(1-\eta_{2} \mu_{1}\right)^{-1} \sum_{i=1}^{\infty} \mu_{2}^{-i} E_{t} \eta_{3} \pi_{t+1+i}+\left(1-\eta_{2} \mu_{1}\right)^{-1} \sum_{i=1}^{\infty} \mu_{2}^{-i} E_{t} \eta_{4} w_{t+i}+ \\
\left(1-\eta_{2} \mu_{1}\right)^{-1} \sum_{i=1}^{\infty} \mu_{2}^{-i} E_{t} \eta_{1} y_{t+i}^{n}+\left(1-\eta_{2} \mu_{1}\right)^{-1} \sum_{i=1}^{\infty} \mu_{2}^{-i} E_{t} \eta_{3} \sigma\left(y_{t+1+i}^{n}-y_{t+i}^{n}-\sigma^{-1}\left(g_{t+1+i}-g_{t+i}\right)\right)+ \\
\left(1-\eta_{2} \mu_{1}\right)^{-1} \sum_{i=1}^{\infty} \mu_{2}^{-i} E_{t}\left(\eta_{1}\left(y_{t+i}-y_{t+i}^{n}\right)+\eta_{3}\left[\sigma\left(\left(y_{t+1+i}-y_{t+1+i}^{n}\right)-\left(y_{t+i}-y_{t+i}^{n}\right)\right)\right]\right)
\end{gathered}
$$

in Woodford (2003). 
This equation expresses current real money balances in terms of future expected natural output, future expected output gaps, future expected inflation and money demand shocks (along with the conventional-static-determinants reflected in the first four terms). When $d=0$ all the forward looking terms will disappear and money demand will be given by a static function in terms of output, nominal interest rate and the money demand shock. Hence, to the extent that variation in $m_{t}$ is not accounted for by output and the nominal interest rate it will reflect movements in future (expected) natural rates of output and output gaps. Thus, real money balances will contain information about the natural rate of output and the output gap beyond that contained in the static determinants of money demand (i.e. output and nominal interest rate). Therefore, any estimation procedure that neglects real money balances may miss useful information about the natural rate of output. Given that the natural rate of output is a summary statistic for some of the shocks (i.e. state variables) of the model—in this case preference and supply shocks-real money balances contain information about the state of the economy and is therefore useful for the conduct of monetary policy.

\subsubsection{Monetary policy}

We need finally to close the model. We specify an interest feedback rule for this purpose, as followed by the monetary authority. The rule specifies how the central bank adjusts the nominal short-term interest rate to variations in inflation, output and the nominal money growth. The adjustment is gradual and the degree of interest rate smoothing is captured by the parameter $\alpha_{r}$. Several considerations motivate the presence of money in the policy rule. One may refer to the former member of the executive Board of the ECB Otmar Issing who argues very strongly that money should never be ignored either in monetary policy or in research (Issing (2006)). Another more realistic justification has been put forward by Goodhart (2007), who argues that monetary aggregate developments should not be totally ignored as they can provide useful information to policy makers in the conduct of monetary policy. There is also empirical evidence supporting the inclusion of money into interest rate rules in estimated models using US data (Ireland (2001) Ireland (2003)). The rule we have just referred to takes the form:

$$
r_{t}=\alpha_{r} r_{t-1}+\left(1-\alpha_{r}\right)\left(\alpha_{\pi} \pi_{t}+\alpha_{y} y_{t}+\alpha_{m} \mu_{t}\right)+\varepsilon_{r t}
$$

We assume $\alpha_{\pi}, \alpha_{y}, \alpha_{m}>0,0<\alpha_{r}<1$ and $\mu_{t}=m_{t}-m_{t-1}+\pi_{t}$ denotes nominal money growth. In (3.11) $\varepsilon_{r t}$ is a monetary policy shock which is assumed to follow an $\operatorname{AR}(1)$ process, $\varepsilon_{r t}=\rho_{r} \varepsilon_{r, t-1}+\epsilon_{r t}$, where $\epsilon_{r t}$ is distributed iid normal with zero mean and standard deviation $\sigma_{r}$.

\section{Estimation methodology and results}

The model presented in the previous sections consists of the following equations: equation (3.2); the Phillips curve, equation (3.7); money demand, equation (3.4); the monetary policy rule, equation (3.11); and the AR(1) processes for the four shocks that buffet the economy. This type of structural DSGE model is better equipped to investigate the role of money over and above what is implied by the static relationship with other forward looking variables. In contrast, single equation models, regardless of their forecasting performance, can be misspecified and inadequately equipped to address such issues. The model is estimated 
with Bayesian techniques using US data on four macroeconomic variables. Bayesian methods for estimating and evaluating the (forecasting) performance of macroeconomic models have gained ground recently. A number of researchers have estimated variants of the New Keynesian model highlighting different frictions in order to shed light on the propagation of shocks and provide quantitative assessments of their importance. Recently, these models have become a standard tool for policy analysis in central banking institutions. ${ }^{7}$ The model's solution is expressed in a state-space form and the Kalman filter is used to evaluate the likelihood function. We employ data on output, inflation, nominal interest rate and real money balances. Output is measured by real GDP, inflation is measured by changes in the GDP deflator, nominal interest rate by the 3-month Treasury bill rate and real money balances as the stock of M2 divided by the GDP deflator. Output and real money balances are expressed in per capita terms by dividing with the civilian noninstitutional population age 16 and over. All data except the interest rate are in logs, demeaned, seasonally adjusted and cover the period from 1959 II to 2007 IV. ${ }^{8}$ Moreover, to ensure consistency with the model's concepts which fluctuate around constant means we de-trend the data for output and real money balances with linear trends since these series exhibit secular growth during the sample period.

The Bayesian approach we adopt combines prior (non-sample) information along with information contained in the data. Let $\Theta$ denote the vector that contains all the structural parameters of the model. The non-sample information is summarized with a prior distribution with density $p(\Theta) .{ }^{9}$ The sample information (conditional on model $\mathcal{M}_{i}$ ) is contained in the likelihood function, $\mathcal{L}\left(\Theta \mid \mathbf{Y}_{T}, \mathcal{M}_{i}\right)$, where $\mathbf{Y}_{T}=\left[Y_{1}, \ldots, Y_{T}\right]$ contains the data. The likelihood function allows us to update the prior distribution of $\Theta$. Let $p\left(\mathbf{Y}_{T} \mid \Theta, \mathcal{M}_{i}\right)=\mathcal{L}\left(\Theta \mid \mathbf{Y}_{T}, \mathcal{M}_{i}\right)$ denote the likelihood function of version $\mathcal{M}_{i}$ of the DSGE model. Then using Bayes' theorem we can express the posterior distribution of the parameters as:

$$
p\left(\Theta \mid \mathbf{Y}_{T}, \mathcal{M}_{i}\right)=\frac{p\left(\mathbf{Y}_{T} \mid \Theta, \mathcal{M}_{i}\right) p(\Theta)}{p\left(\mathbf{Y}_{T} \mid \mathcal{M}_{i}\right)}
$$

where the denominator, $p\left(\mathbf{Y}_{T} \mid \mathcal{M}_{i}\right)=\int p\left(\Theta, \mathbf{Y}_{T} \mid \mathcal{M}_{i}\right) d \Theta$, in the equation above is the marginal data density conditional on model $\mathcal{M}_{i}$. In Bayesian analysis the marginal data density constitutes a measure of model fit with two dimensions: goodness of in-sample fit and a penalty for model complexity. We will use this measure below to evaluate the importance of different assumptions about money. ${ }^{10}$

A number of parameters is held fixed prior to estimation. We set the discount factor $\beta=0.99$ a conventional value used in the DSGE literature. We set the elasticity of demand $\theta$ equal to 10, implying a steady state markup of prices over wages equal to 11 percent. ${ }^{11}$ Markup estimates as reported by Basu and Fernald (1994) for US data are consistent with this value for $\theta .{ }^{12}$ Finally

\footnotetext{
${ }^{7}$ Some representative studies include Schorfheide (2000), Smets and Wouters (2003), Smets and Wouters (2007), Lubik and Schorfheide (2007). The Bank of England and Bank of Canada are two institutions that devote resources in developing and fine tuning such models.

${ }^{8}$ All data are from FRED database of the Federal Reserve Bank of St.Louis.

${ }^{9} \mathrm{We}$ assume that parameters are a priori independent from each other. This is a widely used assumption in the applied DSGE literature and implies the joint prior distribution equals the product of marginal priors.

${ }^{10}$ The posterior distribution of parameters is evaluated numerically using the Metropolis-Hastings algorithm. We also calculate convergence diagnostics in order to check and ensure the stability of the posterior distributions of parameters as described in Brooks and Gelman (1998).

${ }^{11} \beta$ and $\theta$ are related to steady state values but since we use demeaned data it will be difficult to identify them.

${ }^{12}$ This is a common value used in estimated DSGE models (see for example Bouakez et al. (2005)). This parameter is clearly not identified as it appears only in the Phillips curve equation. We also experimented with $\theta=6$ another commonly used value without any material change in the estimation results.
} 
the parameters $h$ and $\psi$ may be poorly identified. Thus we fix the habit persistent parameter, $h$ to 0.85 , a value that is consistent with the range of estimates reported in other studies. ${ }^{13}$

The first five columns in Table 1 list the parameters and the assumptions on the prior distributions. We use fairly loose priors for all parameters. The location of the parameters follows closely the prior specifications used by Smets and Wouters (2007) for the US economy. We briefly discuss parameters which are not common. We assume that the parameter that captures portfolio adjustment cost $(d)$ is centered around 2 with a standard deviation equal to 1 . This value is implied by the calibration in Christiano and Gust (1999). We set the prior mean for the inverse interest elasticity of real money balances ( $\gamma$, corresponding to a static money demand specification) equal to 10 (implying a 0.1 interest rate elasticity) with a standard deviation equal to 5. The rule-of-thumb parameter is centered around 0.5 with a standard deviation of 0.2 , following evidence from Campbell and Mankiw (1989). The parameters for the interest rate feedback rule are set in accordance to the Taylor principle. For instance the long-run coefficients for inflation and output are centered around 1.5 and 0.125 (0.5 divided by four to reflect the quarterly frequency). ${ }^{14}$ The parameter that determines the response to money growth, $a_{\mu}$ is centered at 0.125 with a standard deviation of 0.125. This value is at the lower bound of estimates reported by Ireland (2003) or Ireland (2001). The standard deviations of the innovations follow inverse gamma distributions with a mean of 0.02 and two degrees of freedom, corresponding to a loose prior. The persistence parameters for the AR(1) processes follow beta distributions with a mean of 0.5 and standard deviation of 0.2 . We estimate three models. Model $A$ is the unrestricted model as described in section 3 . Model $B$ imposes the restriction $(d=0)$ reflecting a static money demand, while model $C$ is a standard sticky price model that does not allow, in fact completely denies any role for money, either through the specification of a money demand or through the interest rate feedback rule. Consequently five of the parameters that appear in models $A$ and $B$ are not present in model $C$.

The first notable aspect of the estimation results we draw attention to concerns the importance of money. This is reflected in a significant estimate of nominal money growth in the interest rate feedback rule as reflected in the policy rule coefficient $\alpha_{\mu}$, as well as the positive and significantly different from zero estimate of the portfolio adjustment cost parameter, $d$, supporting the forward-looking nature of money demand. Further, and as previously explained in section 3, $d$ is a key parameter that determines money's role as an information variable.

Nevertheless, the fact that $d$ is significantly different from zero by itself is not a sufficient reason to dismiss the static money demand formulation (i.e. model $B$ ) because in Bayesian analysis we also want to consider (and penalize) the fact that model $A$ is more complex compared to model $B$. To further support the claim about the usefulness of money as an information variable we formally test the hypothesis $d=0$ against $d>0$-equivalently we compare models $A$ and $B$, thus combining both dimensions (goodness of fit and model complexity), using the marginal data densities. ${ }^{15}$ In the Bayesian context this hypothesis can be

\footnotetext{
${ }^{13}$ For example, Smets and Wouters (2007), Christiano et al. (2005), Fuhrer (2000), Boldrin et al. (2001). We have also undertaken a sensitivity analysis by varying $h$ between 0.8 to 0.9 . While there were some differences in parameter estimates the overall results were broadly similar.

${ }^{14}$ Notice however that the presence of money growth in the policy rule implies that the Taylor principle now generalizes to $\alpha_{\pi}+\alpha_{\mu}>1$ for the model to be consistent with a unique rational expectations equilibrium.

${ }^{15}$ When $d=0$ money demand reduces to a purely static specification and thus cannot contain additional information about the state of the economy conditional on output, inflation and the nominal interest rate.
} 
naturally evaluated using the posterior odds ratio which is given by,

$$
\frac{\pi_{\mathcal{M}_{\mathcal{B}}}}{\pi_{\mathcal{M}_{\mathcal{A}}}} \cdot \frac{p\left(Y_{T} \mid \mathcal{M}_{\mathcal{B}}\right)}{p\left(Y_{T} \mid \mathcal{M}_{\mathcal{A}}\right)}
$$

where the first term is the prior odds ratio and the second term the Bayes factor formed by the ratio of the marginal data densities (denominator of (4.1)). The log marginal data densities for models $\mathcal{M}_{\mathcal{B}}, \mathcal{M}_{\mathcal{A}}$ are equal to 3155.8, 3160.9 respectively. Assuming a prior odds ratio of one this calculation yields a posterior odds ratio equal to $0.006(\exp (-5.1))$, which leads us to favour model $\mathcal{M}_{A}$ and reject the hypothesis $d=0$. We also highlight the fact that in the Bayesian context the higher marginal likelihood of model $A$ compared to model $B$ will be reflected in an improvement of predictive out-of-sample ability when using model $A$ to generate forecasts, an important consideration for central banks engaging in inflation forecast targeting. ${ }^{16}$ Figure 1 provides visual evidence for the usefulness of money, by plotting natural rates of output estimates along the uncertainty surrounding these estimates generated from models $A, B$ and $C$. Figure 1 clearly shows that the $5 \%-95 \%$ confidence bands are tighter around the estimates from model $A$ compared to model $B$ or $C$ although somewhat less so for the latter. This indicates that money conveys useful information about the state of the economy thereby supporting the conduct of monetary policy. We note that our results have an interesting parallel and corroborate the findings in Boivin and Giannoni (2006). Boivin and Giannoni (2006) demonstrate the usefulness of a wide range of variables (including monetary aggregates) in providing information for the model's state variables-preference and supply shocks. A key difference is that the simplicity of our framework allows us to be explicit on the structural interpretation for the role of the monetary aggregate while in Boivin and Giannoni (2006) this role is modelled as reduced form. ${ }^{17}$

The parameter estimates from model $A$ are in general broadly similar compared to the standard moneyless sticky price model, $\mathcal{M}_{C}$. Thus, the inclusion of money does not seem to go against the available estimates from a more standard specification, although there are some differences. There are also some notable differences in the parameter estimates depending on the assumptions of how money enters the model that are worth discussing. Going from model $A$ to model $B$ we note that differences arise with respect to the parameter that governs the intertemporal elasticity of substitution $(\sigma)$, where model $A$ produces a considerably higher estimate compared to model $B$. The estimate produced by model $A$ is more in line with existing evidence from estimated DSGE models (e.g. Smets and Wouters (2005)). Notice that in the absence of habit formation, $h=0$ and rule of thumb behaviour, $\psi=1$ this implies that the intertemporal elasticity of substitution in consumption (inverse of $\sigma$ ) suggested by model $A$ is considerably lower compared to model $B$. In model $B$ however, this higher elasticity is reduced by the lower $\psi$ estimate, since the elasticity of substitution with respect to the ex-ante real interest rate is a function of both $\sigma$ and $\psi$. The latter is an important parameter for the design of monetary policy rules. This determines the fraction of rule of thumb-(1- $\psi)-$ households and as can be seen from Table 1 is also estimated to be quantitatively different across models. For example, rule of

\footnotetext{
${ }^{16}$ This follows since in this context the marginal likelihood is a summary statistic for a model's out-of-sample predictive performance. The marginal data density of a model is directly related to the predictive density of a model through the equality, $p\left(\mathbf{Y}_{T} \mid \mathcal{M}_{i}\right)=$ $\prod_{t=1}^{T} p\left(y_{t} \mid \mathbf{Y}_{t-1}, \mathcal{M}_{i}\right)=\int_{\Theta} \prod_{t=1}^{T} p\left(y_{t} \mid \mathbf{Y}_{t-1}, \mathcal{M}_{i}, \Theta\right) p\left(\Theta \mid \mathbf{Y}_{t-1}, \mathcal{M}_{i}\right) d \Theta$.

${ }^{17}$ In principle a wide range of indicators could be driven by and thus related to the model's state vector. Thus, Boivin and Giannoni (2006) argue these variables can be used in the estimation of DSGE models and where they contain information about the model's state it should make estimation more efficient.
} 
thumb behaviour is much more important when the static money demand specification is imposed. Model $B$ suggests that $60 \%$ of households follow a rule of thumb in setting consumption and real money balance holdings. By contrast, model $A$ implies that the fraction of rule of thumb households is only $8 \%$. Why do two very similar models produce these rather different estimates? Since the only difference between the two models is the specification of money demand (static vs. dynamic) the money demand equation can provide a clue. Notice from equation 3.5 than when the static specification of money demand is imposed $(d=0)$ the only parameter that can adjust to fit the dynamics of real money balances in the data is $\psi$. In the data, per capita real money balances are very persistent (first order autocorrelation is equal to 0.98 ) so model $B$ assigns a relatively large value to (1- $\psi$ ) in the attempt to match the high persistence of real money balances. The large difference with respect to the rule-of-thumb parameter, $\psi$, may be important since different shares of rule of thumb households imply different policy prescriptions for monetary policy when re-acting to shocks. Amato and Laubach (2003), for example, show that the response coefficients in interest rate feedback rules differ significantly depending on the importance of rule-of-thumb behaviour in consumption. Furthermore, Galí et al. (2004) demonstrate that in an economy with rule-of-thumb consumers the Taylor principle does not guarantee a unique rational expectations equilibria, suggesting that monetary policy's effectiveness to stabilize the economy is compromised. Both studies above undertake calibration exercises and conduct sensitivity analysis with respect to the rule of thumb parameter. Our fully structural estimate from the preferred specification, i.e. model $A$, suggests that this fraction is very close to the assumption of fully optimising households, suggesting that the rule of thumb behaviour may not be an important concern for policy makers. ${ }^{18}$

Turning to the Taylor rule estimated coefficients, model $A$ assigns a more vigorous response of the nominal interest rate to inflation $\left(\alpha_{\pi}\right)$ but implies that both the output response coefficient $\left(\alpha_{y}\right)$ and the money growth response coefficient $\left(\alpha_{\mu}\right)$ are considerably smaller. Notice, however, that in both models the combined response of the nominal interest rate to inflation and nominal money growth (sum of $\alpha_{\pi}, \alpha_{\mu}$ ) is very similar, so while model $B$ estimates a less vigorous response to inflation this is compensated by a stronger response to nominal money growth. There is also some degree of interest rate inertia in both specifications where model $B$ suggests that the corresponding coefficient $\left(\alpha_{r}\right)$ is somewhat higher compared to model $A$. Further, model $A$ implies a slightly lower degree of price stickiness compared to model $B$. The average duration of prices suggested by model $A$ is equal to a little over 2 quarters compared to nearly 3 quarters implied by model $B .{ }^{19}$ Finally, the interest elasticity of real money demand implied from model $A$ is estimated at -0.13 quite similar to values reported in other studies (e.g. Ireland (2001)). Given the model comparison we undertook above suggests that we should have more confidence to estimates from model $A$ compared to model $B .^{20}$

\footnotetext{
${ }^{18}$ Amato and Laubach (2003) undertake a calibration experiment with $\psi=1,0.6,0.2$. . Both Amato and Laubach (2003) and Galí et al. (2004) find that the fraction of rule of thumb needs to be quite large to materially affect the Taylor principle or the design of optimal interest rate rules.

${ }^{19}$ Interestingly, differences of this sort in structural parameters and consequently the structure of the economy are also highlighted by Boivin and Giannoni (2006) when a wider set of indicators is used in estimation.

${ }^{20}$ Since our goal is to showcase the usefulness of money as an information variable we intentionally keep the model structure as simple as possible. This means that our model will most likely not be as successful in terms of model fit as models with more shocks and frictions such as Smets and Wouters (2007). Thus parameter estimates may reflect the tensions required by a less parameterised model to fit the data. For instance the lower elasticity of intertemporal substitution may reflect the fact that frictions such as investment adjustment costs are found to be important in estimated DSGE models as in Smets and Wouters (2007).
} 
It is important to note that the above results on the role of money do not depend on the rule of thumb assumption. In fact we estimate a new variant of the model removing the rule of thumb consumers (that is, setting $\psi=1$ ). In this variant we estimate the habit persistence parameter, $h$ instead. We do this in order for this variant to be comparable with existing estimated DSGE models in the literature (see, e.g. Smets and Wouters (2007)) but also because habit formation helps account for the persistence present in the data. The results of this estimation are provided in Appendix 2.

\subsection{Sub-sample estimates}

In this section we check the robustness of our results and in particular the conclusion about the role of money as an information variable. We split the full sample in two disjoint periods the first running from 1959 II to 1979 II and the second running from 1982 IV to 2007 IV. Several considerations suggest this exercise. First, a change in the operating procedure of the Federal Reserve that is thought to have begun in 1982 IV, shortly after the appointment of chairman Paul Volcker, and the adoption of a targeting framework for the federal funds rate (see Bernanke and Mihov (1998)). ${ }^{21}$ Second, the post 1980s period is refered to as the 'Great Moderation' and is associated with low and stable inflation as well as lower output volatility. Table 2 reports the parameter estimates in the pre-1979 and post-1982 sub-samples from models $A$ and $B$. There are noticeable differences in the estimates with respect to (i) the coefficients of the interest rate rule, (ii) the standard deviations of the shocks. ${ }^{22}$ In the post-1982 period the response coefficients for output and inflation are estimated to be significantly higher compared to the earlier period, consistent with the results of Clarida et al. (2000). The other difference arises with respect to the standard deviations of the shocks, which are estimated to be smaller in the post-1982 period consistent with the evidence on the 'Great Moderation' ${ }^{23}$ Finally, we evaluate the hypothesis about the information role of money $(d=0$ against $d>0)$ by comparing the marginal data densities of the two models using equation (4.2). Assuming a prior odds ratio of one yields 0.00004 for the pre-1979 period and 0.10 for the post-1982 period, both statistics pointing in favour of model $A$, further supporting the importance of money as an information variable in both sub-samples. ${ }^{24}$

\subsection{The price puzzle: monetary policy and money demand shocks}

The model we analyse can shed light on the price puzzle that seems to plague almost all the empirical work on monetary policy transmission using vector autoregressive (VAR) methods (e.g. Leeper et al. (1996), Christiano et al. (1999)). In this literature a typical finding is that a tightening of policy leads to a rise in the price level (or inflation) — the price puzzle. Recently Leeper and Roush (2003) re-examine this evidence. They expand the typical VAR to encompass various specifications that incorporate

\footnotetext{
${ }^{21}$ We exclude the 1979 III-1982 III period of the Volcker era which is commonly thought to reflect a reserves targeting approach of the Federal Reserve.

${ }^{22}$ There are also some differences to the implied degree of price stickiness and money demand interest elasticity both declining in the post-1982 sample.

${ }^{23}$ We have also examined the sensitivity of the sub-sample estimates to alternatively using a post 1984 I sample corresponding to the beginning of the 'Great moderation' era as suggested by McConnell and Perez-Quiros (2001). Moreover, to take account of trends with respect to inflation and the nominal interest rates in both sub-samples, we have also examined the sensitivity of the results using linearly de-trended inflation and nominal interest rate data. The conclusions about the information role of money remain intact and the estimates for the parameters are broadly similar.

${ }^{24}$ The posterior odds ratio using the 1984 I sub-sample equals 0.05 .
} 
monetary aggregates in the product and money markets. A robust finding is that once monetary aggregates are incorporated into the VAR system then the price puzzle disappears, thereby providing support for the importance of money in the monetary transmission mechanism. ${ }^{25}$ Leeper and Roush (2003) argue that money demand shocks are most likely confounded with monetary policy shocks when money is absent from VARs. Our model can replicate and give a formal illustration of this argument thereby offering a structural explanation consistent with the empirical findings of Leeper and Roush (2003).

To illustrate the price puzzle we estimate a vector autoregression (VAR) on the log of real GDP, log of GDP deflator and the federal funds rate over the period 1959 I to 2007 IV. In order to identify monetary policy shocks we employ the commonly used recursiveness assumption effectively imposing the restriction that monetary policy can only affect the economy with a lag. The responses of GDP, price level and the federal funds rate to a unit standard deviation impulse in the identified shock are shown in Figure 2. Qualitatively these responses are similar to responses one obtains in empirical studies (see for example Christiano et al. (1999)) of the monetary transmission mechanism that use the same identification procedure. Thus, following a tightening of policy we observe a delayed response of output, the federal funds rate to rise and return slowly back to base and a price puzzle, i.e. a zero or initially rising response of the price level before it starts declining with a considerable lag.

A common approach for resolving the price puzzle is to include commodity prices in the VAR. The inclusion of commodity prices is thought to ameliorate the information disadvantage of VARs. In other words too little information in the VAR may confound exogenous policy disturbance with forecastable changes in inflation. But the inclusion of commodity prices raises the question of the exact role of the information content of those prices in policy choices. In this paper we take a different approach. As Leeper and Roush (2003) we view the inclusion of monetary aggregates as an important ingredient in the monetary policy making process. To shed light on the emergence of price puzzle from the lens of our estimated model we present impulse responses to monetary policy and money demand shocks. Figures 3 and 4 present median-and associated $90 \%$ probability bands-responses from model $A$. As is evident from these responses monetary policy and money demand shocks produce (qualitatively) very similar responses for all variables but money and inflation. Both types of shocks are associated with humpshaped declines in output and rises in nominal and real interest rates. However, money demand shocks are associated with a (delayed) increase in inflation and the price level, as well as an increase in real and nominal money balances. By contrast, monetary policy shocks produce opposite movements in those variables. Therefore, the extent to which monetary policy shocks create a price puzzle may depend on whether they are confounded with money demand shocks. This suggests that in empirical work that excludes monetary aggregates these two sources may prohibit correct identification of monetary policy shocks and thus lead to incorrect conclusions about the monetary transmission mechanism. Our analysis, therefore, provides an additional reason why we should think carefully about money in models that seek to explain the monetary transmission mechanism.

Interestingly enough, Leeper and Roush (2003) using monthly US data from 1959 to 2001 report results from a range of VARs highlighting the usefulness of money aggregates in resolving the price puzzle, but also the strength of liquidity effects.

\footnotetext{
${ }^{25}$ Earlier attempts to resolve the price puzzle mostly call for the inclusion of commodity prices in VARs as a source of information for future inflation developments (e.g. Sims (1992)).
} 
In their empirical results small liquidity effects are associated with large price puzzles. Notice that the theoretical (model) responses are also consistent with this empirical finding since money moves in opposite directions depending on the source of the disturbance. In other words, the more confounded the monetary policy shock from money demand disturbances is, the higher the likelihood of a small or no liquidity effect. Finally, it is also worthwhile to stress that our results clearly suggest that empirical work that seeks to properly capture exogenous shifts in monetary policy should take into account the forward looking nature of money demand since it will most likely contribute towards better measurement of money demand shocks. ${ }^{26}$ Our estimated model thus offers a structural framework that replicates qualitatively these empirical results and helps to analyse a potential source for the emergence of a price puzzle. In our model the role of money is confined to an information vehicle. Still, even under this mild interpretation our estimation results highlight the usefulness of monetary aggregates in resolving long-standing monetary puzzles.

\section{Summary and Conclusions}

New Keynesian models used for quantitative and policy evaluation purposes usually assume a trivial role for monetary aggregates. As a consequence, money is entirely neglected from the monetary transmission mechanism. In this paper we estimate a small structural sticky price model that allows a role for money. To do this we depart from the static money demand formulation and posit a forward-looking money demand function instead. The implication is that money can become an information variable that can help produce more precise estimates about the unobserved variables of the model. One such important variable that is crucial for an accurate assessment of the state of the economy is the natural rate of output. The dynamic formulation of money demand is supported by data of the US economy and is robust to the more recent changes in the practice of monetary policy that took place during the 'Great Moderation' period. Consequently, monetary policy makers can use the additional information contained in the monetary aggregates to better gauge the state of the economy. This property of money can be proved useful when accurate assessments of such structural variables are crucial for forecasting purposes, as is the case with inflation-targeting central banks. The inclusion of money in the model can also help resolve a long-standing puzzle in monetary economics, the so called 'price-puzzle'. The small step we make here opens an array of further questions and research. An important such question is the kind, and the broadness, of monetary aggregates upon which policy makers should focus.

\section{References}

Amato, J. and Laubach, T.: 2003, Rule-of-thumb behaviour and monetary policy, European Economic Review 47, 791-831.

Andrés, J., López-Salido, J. D. and Nelson, E.: 2009, Money and the natural rate of interest: structural estimates for the United States and the Euro-Area, Journal of Economic Dynamics and Control 33, 758-776.

\footnotetext{
${ }^{26}$ In fact Leeper and Roush (2003) suggest that money demand in their VARs may not be properly identified because of precisely neglecting this forward looking role.
} 
Andrés, J., López-Salido, J. D. and Vallés, J.: 2006, Money in an estimated business cycle model of the Euro-Area, ECONOMIC JOURNAL 116, 457-77.

Basu, S. and Fernald, J.: 1994, Constant returns and small markups in us manufacturing, International Finance Discussion Paper 483, Federal Reserve Board.

Beck, G. and Wieland, V.: 2007, Money in monetary policy design: A formal characterization of ECB-style cross-checking, Journal of the European Economic Association 5, 524-533.

Bernanke, B.: 2006, Monetary aggregates and monetary policy at the federal reserve: A historical perspective, Speech delivered at the fourth ECB Central Banking Conference on the role of money: Money and Monetary policy in the twenty-first century, Frankfurt, Germany, ECB.

Bernanke, B. and Mihov, I.: 1998, Measuring monetary policy, Quarterly Journal of Economics 113, 869-902.

Boivin, J. and Giannoni, M.: 2006, DSGE models in a data rich environment, Working paper 12772, NBER.

Boldrin, M., Christiano, L. and Fisher, J.: 2001, Habit persistence asset returns and the business cycle, American Economic Review 86, 1154-1174.

Bouakez, H., Cardia, E. and Ruge-Murcia, F.: 2005, Habit formation and the persistence of monetary shocks, Journal of Monetary Economics 52, 1073-88.

Brooks, S. and Gelman, A.: 1998, General methods for monitoring convergence of iterative simulations, Journal of Computational and Graphical Statistics 7, 434-55.

Calvo, G.: 1983, Staggered prices in a utility-maximizing framework, Journal of Monetary Economics 12, $383-398$.

Campbell, J. and Mankiw, G.: 1989, Consumption income and interest rates: Reinterpeting the time series evidence, NBER Macroeconomics Annual 4, 184-246.

Christiano, L. and Eichenbaum, M.: 1992, Liquidity effects and the monetary transmission mechanism, American Economic Review 82, 346-353.

Christiano, L., Eichenbaum, M. and Evans, C.: 1999, Monetary policy shocks: What have we learned and to what end?, The Handbook of Macroeconomics, Volume 1A, Chapter 2, John Taylor and M. Woodford (eds.), Amsterdam: Elsevier Sience Publication .

Christiano, L., Eichenbaum, M. and Evans, C.: 2005, Nominal rigidities and the dynamic effects of a shock to monetary policy, Journal of Political Economy 113, 1-45. 
Christiano, L. and Gust, C.: 1999, Taylor rules in a limited participation model, De Economist 147, 437-460.

Clarida, R., Galí, J. and Gertler, M.: 2000, Monetary policy rules and macroeconomic stability: evidence and some theory, Quarterly Journal of Economics 115, 147-180.

Coenen, G., Levin, A. and Wieland, V.: 2005, Uncertainty and the role of money as an information variable for monetary policy, European Economic Review 49, 975-1006.

Friedman, B.: 2003, The LM curve: A not-so-fond farewell, Working paper 10123, NBER.

Fuhrer, J.: 2000, Habit persistence in consumption and its implications for monetary-policy models, American Economic Review 90, 367-390.

Gabaix, X. and Laibson, D.: 2001, The 6-d bias and the equity premium puzzle, NBER Macroeconomics Annual 16, $257-330$.

Gabaix, X. and Laibson, D.: 2005, Bounded rationality and directed cognition, Mimeo, NYU.

Galí, J.: 2003, New perspectives on monetary policy, inflation, and the business cycle, Advances in Economics and Econometrics, edited by: M. Dewatripont, L. Hansen, and S. Turnovsky, Cambridge University Press 2003 III, 151-197.

Galí, J., López-Salido, J. D. and Vallés, J.: 2004, Rule of thumb consumers and the design of interest rate rules, Journal of Money Credit and Banking 36, 740-63.

Geweke, J.: 1999, Using simulation methods for bayesian econometric models: Inference, development and communication, Econometric Reviews 18, 1-126.

Goodfriend, M. and King, R.: 1997, The new neoclassical synthesis and the role of monetary policy, NBER Macroeconomics Annual 12, 231-296.

Goodhart, C.: 2007, Whatever became of the monetary aggregates?, The Peston lecture delivered in honour of Maurice, Lord Peston, Queen Mary, University of London.

Guiso, L., Haliassos, M. and Jappelli, T.: 2002, Household Portfolios, MIT Press, Cambridge, Massachusetts.

Haliassos, M. and Michaelides, A.: 2002, Calibration and computation of household portfolio models, in Household Portfolios, edited by: L. Guiso and M. Haliassos and T. Jappelli pp. 55-101.

Ireland, P.: 2001, Sticky price models of the business cycle: specification and stability, Journal of Monetary Economics 47, 3-18. Ireland, P.: 2003, Endogenous money or sticky prices?, Journal of Monetary Economics 50, 1623-48.

Ireland, P.: 2004, Money's role in the monetary business cycle, Journal of Money Credit and Banking 36, 969-983. 
Issing, O.: 2006, The ECB's monetary policy strategy: Why did we choose a two-pillar approach?, Paper presented at the fourth ECB Central Banking Conference on the role of money: Money and Monetary policy in the twenty-first century, Frankfurt, Germany, ECB.

Leeper, E. and Roush, J.: 2003, Putting 'M' back in monetary policy, Journal of Money Credit and Banking 35, $1217-56$.

Leeper, E., Sims, C. and Zha, T.: 1996, What does monetary policy do?, Brookings Papers on Economic Activity 2, 1-63.

Lubik, T. and Schorfheide, F.: 2007, Do central banks respond to excange rate movements? A structural investigation, Journal of Monetary Economics 54, 1069-1087.

Lucas, R.: 2007, Central banking: Is science replacing art?, in Monetary Policy: A Journey From Theory to Practice-an ECB colloquium held in honour of Otmar Issing, European Central Bank.

Luttmer, E.: 1999, What level of fixed costs can reconcile consumption and stock returns?, Journal of Political Economy 107, 969-997.

McConnell, M. and Perez-Quiros, G.: 2001, Output fluctuations in the united states: what has changed since the early 1980s?, American Economic Review 90, 1464-76.

Nelson, E.: 2002, Direct effects of base money on aggregate demand: theory and evidence, Journal of Monetary Economics 49, 687-708.

Rotemberg, J. and Woodford, M.: 1997, An optimization-based econometric framework for the evaluation of monetary policy, NBER Macroeconomics Annual 12, 297-361.

Schorfheide, F.: 2000, Loss function-based evaluation of DSGE models, Journal of Applied Econometrics 15, 645-70.

Sims, C.: 1992, Interpreting the macroeconomic time series facts: The effects of monetary policy, European Economic Review 36, 975-1000.

Sims, C.: 2003, The implications of rational inattention, Journal of Monetary Economics 50, 665-690.

Smets, F. and Wouters, R.: 2003, An estimated dynamic stochastic general equilibrium model of the Euro Area, Journal of the European Economic Association 1, 1123-75.

Smets, F. and Wouters, R.: 2005, Comparing shocks and frictions in US and Euro Area business cycles: a bayesian DSGE approach, Journal of Applied Econometrics 20, 161-183.

Smets, F. and Wouters, R.: 2007, Shocks and frictions in US business cycles: A bayesian DSGE approach, American Economic Review 97, 586-606. 
Vissing-Jørgensen, A.: 2002, Limited asset market participation and the elasticity of intertemporal substitution, Journal of Political Economy 110, 825-853.

Woodford, M.: 2003, Interest and Prices: Foundations of a Theory of Monetary Policy, Princeton University Press.

\section{Appendix 1}

This section provides derivation details and briefly describes the equations of the model and the log-linear approximation used in the main text. The solution of the optimising household's choice of consumption $C_{t}^{o}$ yields the familiar Euler equation.

$$
\left(C_{t}^{o}-h C_{t-1}\right)^{-\sigma}=\beta r_{t} E_{t}\left[\left(C_{t+1}^{o}-h C_{t}\right)^{-\sigma}\left(\frac{1}{\pi_{t+1}}\right)\right]
$$

Combing the rule of thumb equation, $C_{t}^{n o}=C_{t-1}$, the definition of total consumption, $C_{t}=\psi C_{t}^{o}+(1-\psi) C_{t}^{n o}$, the goods market equilibrium, $Y_{t}=C_{t}$ and using lower case letters to denote log deviations from the steady state level of output, $y_{t}=\log \left(Y_{t} / Y^{*}\right)$ and the definition of the output gap, $x_{t}=y_{t}-y_{t}^{n}$ we get equation (3.2) in the text.

Similarly, we get an optimality condition that characterise the choice of real money balances for the fraction $\psi$ of optimising households.

$$
\begin{gathered}
w_{t}\left(\frac{M_{t}^{o}}{P_{t}}\right)^{-\gamma}-\frac{\partial \Phi\left(\frac{M_{t}^{o}}{P_{t}}, \frac{M_{t-1}^{o}}{P_{t-1}}\right)}{\partial M_{t}^{o}} P_{t}-\left(C_{t}^{o}-h C_{t-1}\right)^{-\sigma} \\
-\beta E_{t}\left[\frac{\partial \Phi\left(\frac{M_{t+1}^{o}}{P_{t}+1}, \frac{M_{t}^{o}}{P_{t}}\right)}{\partial M_{t}^{o}} P_{t}-\left(C_{t+1}^{o}-h C_{t}\right)^{-\sigma} \frac{1}{\pi_{t+1}}\right]=0
\end{gathered}
$$

Let $m_{t}=\psi m_{t}^{o}+(1-\psi) m_{t}^{n o}$. Using $m_{t}^{n o}=m_{t-1}$ and substituting for $\Phi$ yields equation (3.4) in the text.

The money demand equation (3.9) described in the text can be solved in terms of current and future output, nominal interest rates, and money demand shocks using the method of undetermined coefficients,

$$
m_{t}=\mu_{1} m_{t-1}+\left(1-\eta_{2} \mu_{1}\right)^{-1} \sum_{i=0}^{\infty} \mu_{2}^{-i} E_{t}\left(\eta_{1} y_{t+i}+\eta_{3} r_{t+i}+\eta_{4} w_{t+i}\right)
$$

where $\mu_{1}, \mu_{2}$ is the stable (unstable) root of equation (3.9) respectively. This can be further be written as,

$$
m_{t}=\mu_{1} m_{t-1}+\delta_{0} y_{t}+\tau_{0} r_{t}+\zeta_{0} w_{t}+\left(1-\eta_{2} \mu_{1}\right)^{-1} \sum_{i=1}^{\infty} \mu_{2}^{-i} E_{t}\left(\eta_{1} y_{t+i}+\eta_{3} r_{t+i}+\eta_{4} w_{t+i}\right)
$$

where $\delta_{0}=\left(1-\eta_{2} \mu_{1}\right)^{-1} \eta_{1}, \tau_{0}=\left(1-\eta_{2} \mu_{1}\right)^{-1} \eta_{3}, \zeta_{0}=\left(1-\eta_{2} \mu_{1}\right)^{-1} \eta_{4}$. Further noting that the Phillips curve (eq. (3.7)) and the IS curve (eq. (3.2)) imply,

$$
\pi_{t}=\kappa \sum_{j=0}^{\infty}\left(y_{t+j}-y_{t+j}^{n}\right)
$$




$$
\left(r r_{t}-r r_{t}^{n}\right)=\sigma E_{t}\left(\left(y_{t+1}-y_{t+1}^{n}\right)-\left(y_{t}-y_{t}^{n}\right)\right)
$$

respectively and using the Fisher equation, $r_{t}=r r_{t}+E_{t} \pi_{t+1}$, where $r r_{t}$ denotes the real interest rate, we can express the equation above as,

$$
\begin{gathered}
m_{t}=\mu_{1} m_{t-1}+\delta_{0} y_{t}+\tau_{0} r_{t}+\zeta_{0} w_{t}+\left(1-\eta_{2} \mu_{1}\right)^{-1} \sum_{i=1}^{\infty} \mu_{2}^{-i} E_{t} \eta_{1} y_{t+i}^{n}+\left(1-\eta_{2} \mu_{1}\right)^{-1} \sum_{i=1}^{\infty} \mu_{2}^{-i} E_{t} \eta_{3} r r_{t+i}^{n}+ \\
\left(1-\eta_{2} \mu_{1}\right)^{-1} \sum_{i=1}^{\infty} \mu_{2}^{-i} E_{t}\left(\eta_{1}\left(y_{t+i}-y_{t+i}^{n}\right)+\eta_{3}\left(r r_{t+i}-r r_{t+i}^{n}\right)+\eta_{4} w_{t+i}\right)+\left(1-\eta_{2} \mu_{1}\right)^{-1} \sum_{i=1}^{\infty} \mu_{2}^{-i} E_{t} \eta_{3} \pi_{t+1+i}
\end{gathered}
$$

Finally using the definition for the natural rate of interest (eq. (3.3)) we can readily substitute in the equation above to get equation (3.10) in the main text. 
Table 1: Prior and Posterior distributions-Full sample

\begin{tabular}{|c|c|c|c|c|c|c|c|c|c|c|c|c|c|}
\hline & \multirow{3}{*}{ Description } & \multicolumn{6}{|c|}{$\mathcal{M}_{A}$} & \multicolumn{3}{|c|}{$\mathcal{M}_{B}$} & \multicolumn{3}{|c|}{$\mathcal{M}_{C}$} \\
\hline & & \multicolumn{3}{|c|}{$\underline{\text { Prior distribution }}$} & \multicolumn{3}{|c|}{ Posterior distribution } & \multicolumn{3}{|c|}{$\underline{\text { Posterior distribution }}$} & \multicolumn{3}{|c|}{$\underline{\text { Posterior distribution }}$} \\
\hline & & Distr. & Mean & Std.dev. & Mean & $5 \%$ & $95 \%$ & Mean & $5 \%$ & $95 \%$ & Mean & $5 \%$ & $95 \%$ \\
\hline$\lambda$ & Inverse labour elasticity & Gamma & 2 & 1 & 0.95 & 0.61 & 1.34 & 1.21 & 0.74 & 1.66 & 0.75 & 0.54 & 0.96 \\
\hline$\sigma$ & Inverse intertemporal elasticity & Gamma & 1.5 & 0.5 & 2.47 & 2.00 & 2.96 & 0.41 & 0.28 & 0.54 & 1.58 & 0.93 & 2.20 \\
\hline$\psi$ & Share of optimising & Beta & 0.5 & 0.2 & 0.92 & 0.87 & 0.97 & 0.40 & 0.31 & 0.50 & 0.95 & 0.90 & 0.99 \\
\hline$\xi$ & Calvo prices & Beta & 0.5 & 0.2 & 0.54 & 0.46 & 0.62 & 0.62 & 0.54 & 0.72 & 0.59 & 0.49 & 0.70 \\
\hline$d$ & Portfolio adjustment & Gamma & 2 & 1 & 0.92 & 0.08 & 1.74 & 0 & n.a. & n.a. & n.a. & n.a. & n.a. \\
\hline$\gamma$ & Inverse money demand elasticity & Gamma & 10 & 5 & 6.97 & 4.41 & 9.52 & 7.59 & 5.45 & 9.67 & n.a. & n.a. & n.a. \\
\hline$\alpha_{r}$ & Taylor rule smoothing & Beta & 0.5 & 0.2 & 0.31 & 0.15 & 0.46 & 0.43 & 0.26 & 0.59 & 0.21 & 0.10 & 0.32 \\
\hline$\alpha_{y}$ & Taylor rule output & Gamma & 0.125 & 0.125 & 0.08 & 0.00 & 0.15 & 0.16 & 0.05 & 0.26 & 0.09 & 0.00 & 0.16 \\
\hline$\alpha_{\pi}$ & Taylor rule inflation & Gamma & 1.5 & 0.5 & 1.99 & 1.37 & 2.57 & 1.50 & 0.95 & 2.05 & 2.05 & 1.51 & 2.60 \\
\hline$\alpha_{\mu}$ & Taylor rule money & Gamma & 0.125 & 0.125 & 0.64 & 0.43 & 0.86 & 0.92 & 0.64 & 1.20 & n.a. & n.a. & n.a. \\
\hline$\rho_{g}$ & Preference & Beta & 0.5 & 0.2 & 0.36 & 0.25 & 0.47 & 0.37 & 0.26 & 0.48 & 0.38 & 0.27 & 0.48 \\
\hline$\rho_{z}$ & Technology & Beta & 0.5 & 0.2 & 0.95 & 0.92 & 0.98 & 0.92 & 0.87 & 0.96 & 0.95 & 0.93 & 0.98 \\
\hline$\rho_{m}$ & Money demand & Beta & 0.5 & 0.2 & 0.94 & 0.90 & 0.97 & 0.95 & 0.93 & 0.98 & n.a. & n.a. & n.a. \\
\hline$\rho_{r}$ & Monetary policy & Beta & 0.5 & 0.2 & 0.76 & 0.70 & 0.83 & 0.74 & 0.64 & 0.84 & 0.83 & 0.76 & 0.90 \\
\hline$\sigma_{g}$ & Preference & InvGamma & 0.02 & $2^{*}$ & 0.15 & 0.12 & 0.18 & 0.06 & 0.05 & 0.08 & 0.10 & 0.06 & 0.13 \\
\hline$\sigma_{z}$ & Technology & InvGamma & 0.02 & $2^{*}$ & 0.03 & 0.02 & 0.04 & 0.03 & 0.02 & 0.05 & 0.014 & 0.01 & 0.02 \\
\hline$\sigma_{r}$ & Monetary policy & InvGamma & 0.02 & $2^{*}$ & 0.005 & 0.003 & 0.006 & 0.005 & 0.003 & 0.006 & 0.005 & 0.003 & 0.006 \\
\hline$\sigma_{m}$ & Money demand & InvGamma & 0.02 & $2^{*}$ & 0.21 & 0.17 & 0.24 & 0.16 & 0.14 & 0.18 & n.a. & n.a. & n.a. \\
\hline & Log marginal density & & & & & 3160.9 & & & 3155.8 & & & 2448.2 & \\
\hline
\end{tabular}

Notes. Posterior distributions are obtained using the Metropolis-Hastings algorithm with 250,000 draws after discarding the first 50,000 draws. For the Inverse Gamma distribution the degrees of freedom are reported. $\mathcal{M}_{A}$ is the model with a forward looking money demand and money in the policy rule. $\mathcal{M}_{B}$ is the model with a static money demand and money in the policy rule. $\mathcal{M}_{C}$ is a conventional money-less NK model that abstracts from money entirely. To test the stability of the posterior samples we use the methods described in Brooks and Gelman (1998). The Log marginal data density is computed using the modified harmonic mean estimator of Geweke (1999). Model favoured by the data attains the highest marginal data density.

\section{Appendix 2}

This section presents estimation results for a variant of our model where all households are optimising. To obtain this variant we set $\psi=1$ and estimate the habit persistence parameter, $h$ instead. Tables 3 and 4 report the estimation results for the full and sub-samples respectively. A comparison of the marginal data densities shown in the last row of Tables 3 and 4 reveals that model $A$ is the preferred version compared to model $B$, thus supporting our conclusions on the role of money as an information variable. Our results are thus fully robust to this model perturbation. This is true both in the full and sub-samples. 
Table 2: Posterior distributions-Subsamples

\begin{tabular}{|c|c|c|c|c|c|c|c|c|c|c|c|c|c|}
\hline & \multirow{4}{*}{ Description } & \multicolumn{6}{|c|}{ Pre-1979 } & \multicolumn{6}{|c|}{ Post-1982 } \\
\hline & & \multirow{2}{*}{\multicolumn{3}{|c|}{$\begin{array}{c}\qquad \mathcal{M}_{A} \\
\text { Posterior distribution }\end{array}$}} & \multicolumn{3}{|c|}{$\mathcal{M}_{B}$} & \multicolumn{3}{|c|}{$\mathcal{M}_{A}$} & \multicolumn{3}{|c|}{$\mathcal{M}_{B}$} \\
\hline & & & & & \multicolumn{3}{|c|}{$\underline{\text { Posterior distribution }}$} & \multicolumn{3}{|c|}{$\underline{\text { Posterior distribution }}$} & \multicolumn{3}{|c|}{$\underline{\text { Posterior distribution }}$} \\
\hline & & Mean & $5 \%$ & $95 \%$ & Mean & $5 \%$ & $95 \%$ & Mean & $5 \%$ & $95 \%$ & Mean & $5 \%$ & $95 \%$ \\
\hline$\lambda$ & Inverse labour elasticity & 0.68 & 0.32 & 1.05 & 0.84 & 0.36 & 1.13 & 1.32 & 0.82 & 1.77 & 1.42 & 0.96 & 1.88 \\
\hline$\sigma$ & Inverse intertemporal elasticity & 2.05 & 1.44 & 2.58 & 0.20 & 0.09 & 0.29 & 3.02 & 2.61 & 3.39 & 0.71 & 0.46 & 0.92 \\
\hline$\psi$ & Share of optimising & 0.93 & 0.87 & 0.98 & 0.36 & 0.23 & 0.48 & 0.93 & 0.88 & 0.99 & 0.62 & 0.49 & 0.75 \\
\hline$\xi$ & Calvo prices & 0.53 & 0.43 & 0.63 & 0.60 & 0.48 & 0.69 & 0.43 & 0.32 & 0.55 & 0.46 & 0.36 & 0.55 \\
\hline$d$ & Portfolio adjustment & 0.69 & 0.07 & 1.25 & n.a. & n.a. & n.a. & 1.17 & 0.30 & 1.95 & n.a. & n.a. & n.a. \\
\hline$\gamma$ & Inverse money demand elasticity & 4.42 & 1.43 & 7.77 & 5.80 & 3.77 & 7.99 & 8.47 & 5.83 & 11.10 & 9.02 & 6.83 & 11.15 \\
\hline$\alpha_{r}$ & Taylor rule smoothing & 0.40 & 0.22 & 0.58 & 0.38 & 0.18 & 0.60 & 0.45 & 0.30 & 0.50 & 0.33 & 0.13 & 0.53 \\
\hline$\alpha_{y}$ & Taylor rule output & 0.08 & 0.00 & 0.16 & 0.12 & 0.02 & 0.23 & 0.18 & 0.04 & 0.32 & 0.21 & 0.08 & 0.34 \\
\hline$\alpha_{\pi}$ & Taylor rule inflation & 1.98 & 1.34 & 2.66 & 1.43 & 0.90 & 2.10 & 2.53 & 1.80 & 3.22 & 1.93 & 1.31 & 2.52 \\
\hline$\alpha_{\mu}$ & Taylor rule money & 0.75 & 0.40 & 1.11 & 1.07 & 0.65 & 1.42 & 0.45 & 0.25 & 0.63 & 0.68 & 0.44 & 0.90 \\
\hline$\rho_{g}$ & Preference & 0.32 & 0.16 & 0.48 & 0.30 & 0.15 & 0.48 & 0.52 & 0.39 & 0.64 & 0.60 & 0.47 & 0.73 \\
\hline$\rho_{z}$ & Technology & 0.96 & 0.93 & 0.99 & 0.91 & 0.86 & 0.97 & 0.95 & 0.92 & 0.98 & 0.93 & 0.89 & 0.98 \\
\hline$\rho_{m}$ & Money demand & 0.88 & 0.81 & 0.97 & 0.92 & 0.88 & 0.97 & 0.96 & 0.93 & 0.98 & 0.96 & 0.94 & 0.98 \\
\hline$\rho_{r}$ & Monetary policy & 0.77 & 0.69 & 0.86 & 0.75 & 0.65 & 0.87 & 0.73 & 0.64 & 0.83 & 0.67 & 0.55 & 0.78 \\
\hline$\sigma_{g}$ & Preference & 0.14 & 0.10 & 0.18 & 0.04 & 0.02 & 0.05 & 0.13 & 0.10 & 0.15 & 0.05 & 0.04 & 0.07 \\
\hline$\sigma_{z}$ & Technology & 0.02 & 0.01 & 0.03 & 0.03 & 0.01 & 0.035 & 0.016 & 0.012 & 0.02 & 0.012 & 0.01 & 0.02 \\
\hline$\sigma_{r}$ & Monetary policy & 0.005 & 0.003 & 0.006 & 0.004 & 0.003 & 0.006 & 0.004 & 0.003 & 0.005 & 0.004 & 0.003 & 0.006 \\
\hline$\sigma_{m}$ & Money demand & 0.27 & 0.14 & 0.47 & 0.14 & 0.11 & 0.16 & 0.13 & 0.10 & 0.15 & 0.10 & 0.09 & 0.12 \\
\hline & Log marginal density & \multicolumn{3}{|c|}{1294.4} & \multicolumn{3}{|c|}{1284.6} & \multicolumn{3}{|c|}{1734.6} & \multicolumn{3}{|c|}{1732.4} \\
\hline
\end{tabular}

Notes. Posterior distributions are obtained using the Metropolis-Hastings algorithm with 250,000 draws after discarding the first 50,000 draws. For the Inverse Gamma distribution the degrees of freedom are reported. $\mathcal{M}_{A}$ is the model with a forward looking money demand and money in the policy rule. $\mathcal{M}_{B}$ is the model with a static money demand and money in the policy rule. To test the stability of the posterior samples we use the methods described in Brooks and Gelman (1998). The Log marginal data density is computed using the modified harmonic mean estimator described in Geweke (1999). Model favoured by the data attains the highest marginal data density. 
Figure 1: Potential output estimates with 90 percent confidence bands
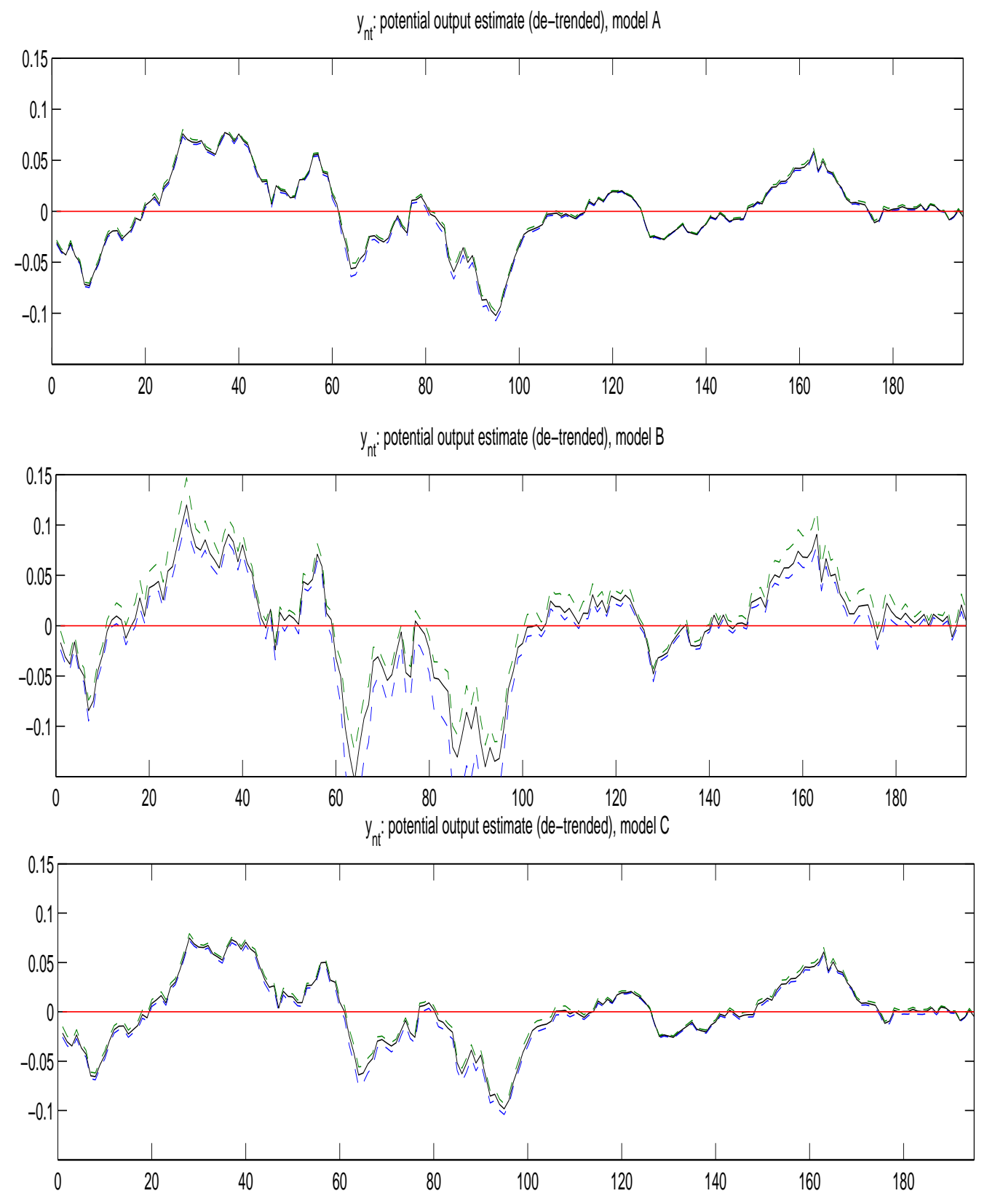

Notes. Figure 1 depicts the potential level of output as implied by the estimated models in Table 1 . These estimates are constructed using the estimates from the smoothed shocks (using all available information in the sample) implied by each model. Periods in quarters. 
Figure 2: Responses to a contractionary (one unit std.dev.) monetary policy shock: U.S. data
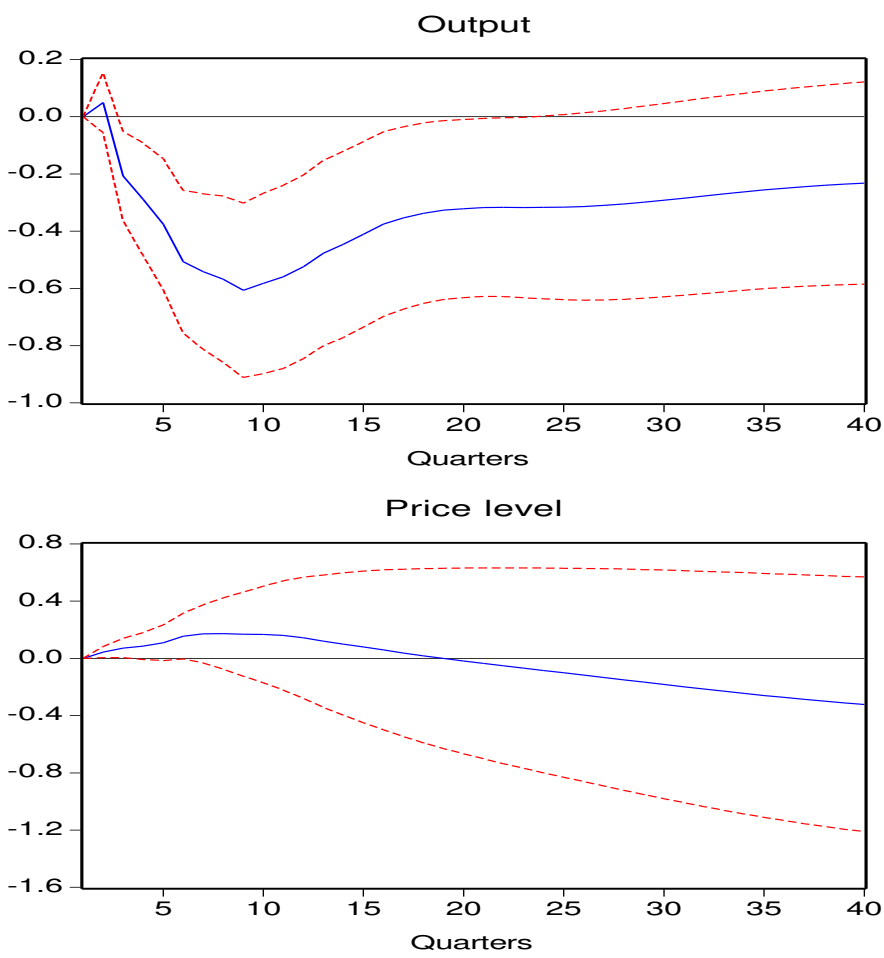

Federal funds rate

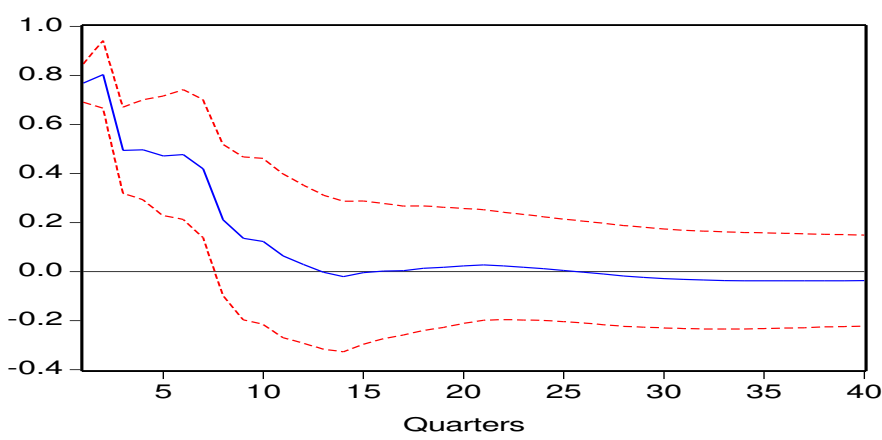

Notes. Figure 2 depicts impulse responses with 2 standard error confidence bands from a tri-variate vector autoregression with 6 lags (based on the Akaike information criterion) estimated on U.S. data using the log of real

GDP, $\log$ of the implicit GDP deflator and the federal funds rate. The estimation sample is 1959 I to 2007 IV. 
Figure 3: Responses to one (positive) unit std.dev. monetary policy shock: model A
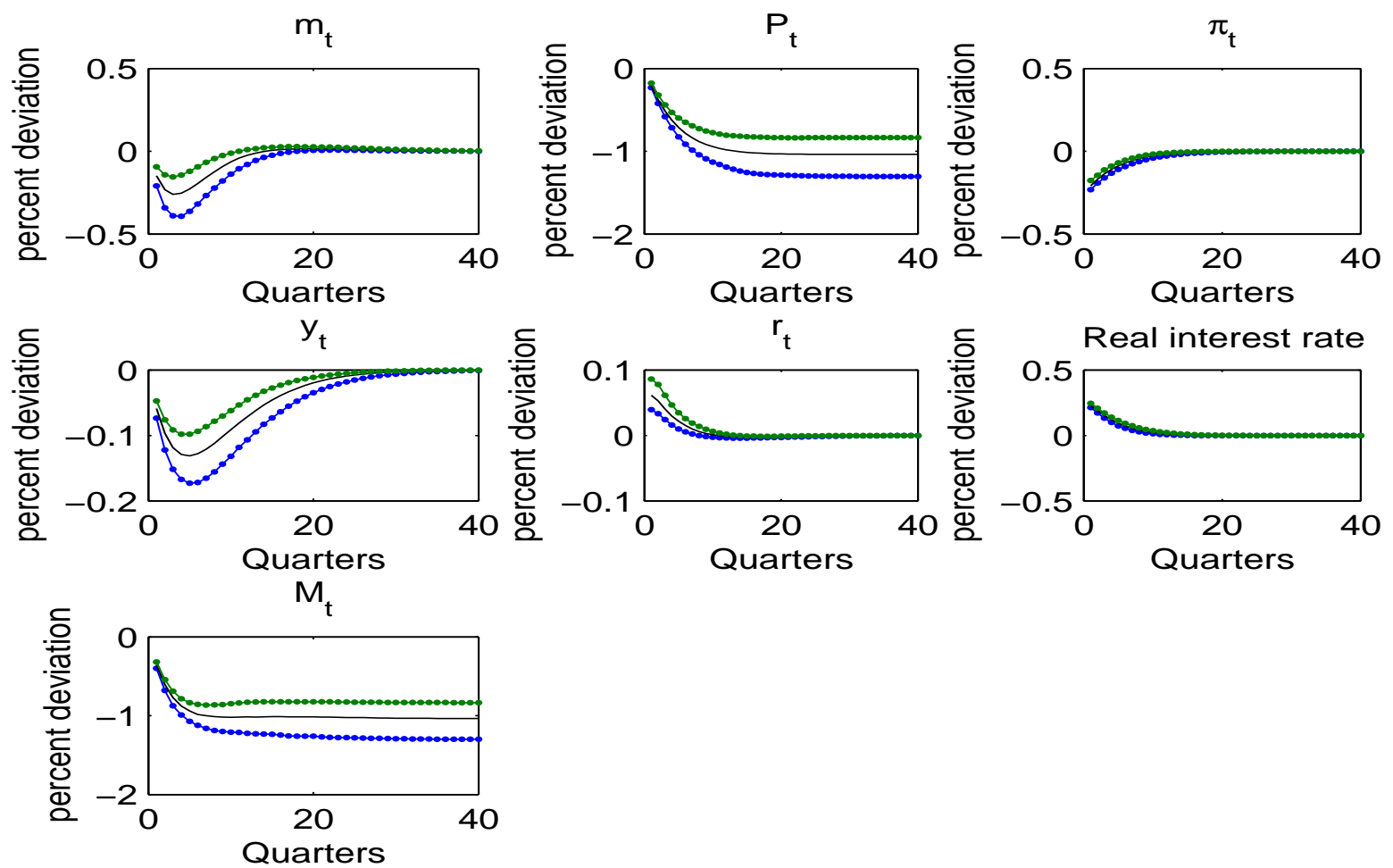

Figure 4: Responses to one (positive) unit std.dev. money demand shock: model A
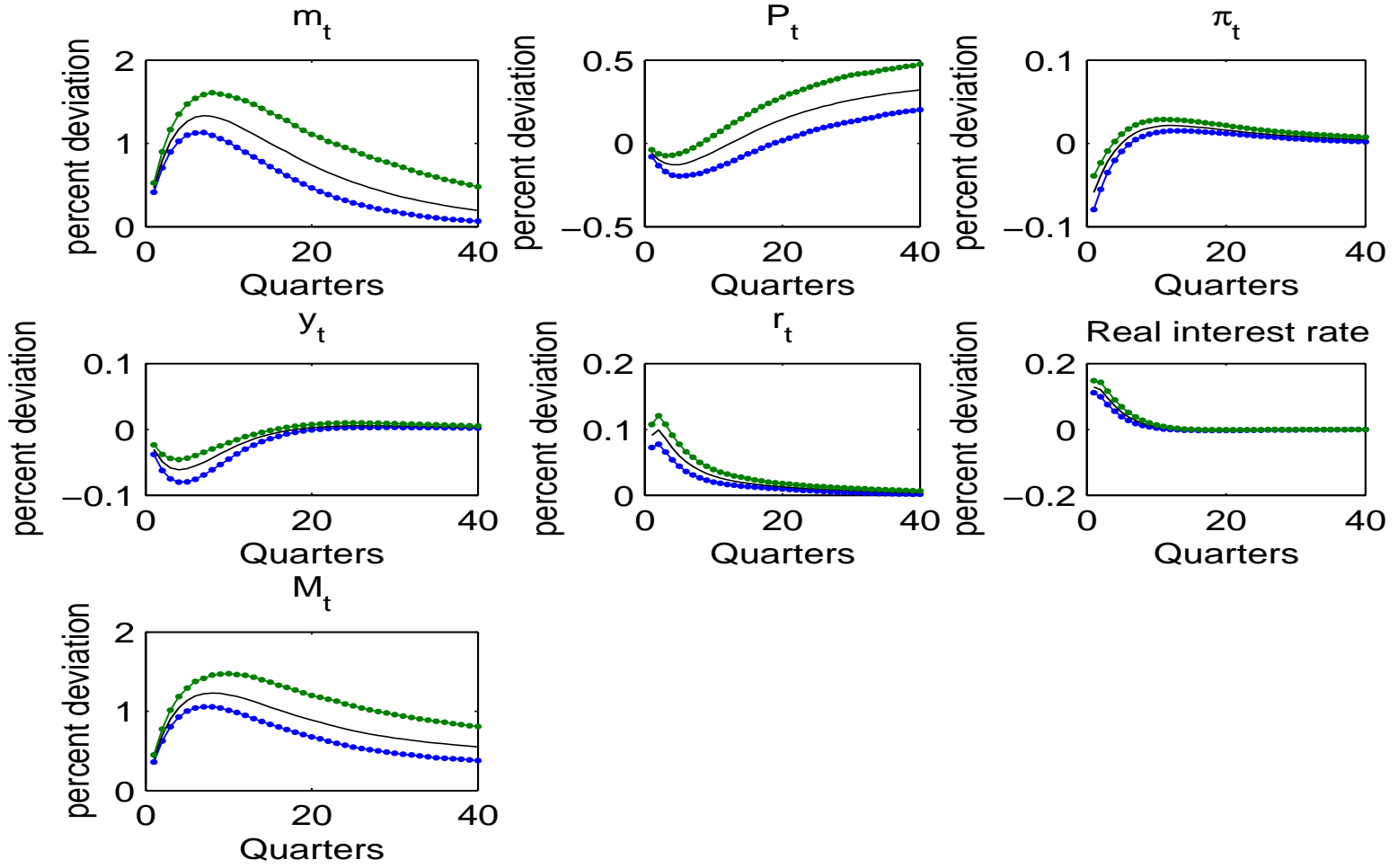

Notes. Figures 3 and 4 depict median impulse responses (solid lines) with associated $90 \%$ probability bands. $m_{t}=$ real money balances, $P_{t}=$ price level, $\pi_{t}=$ Inflation, $y_{t}=$ Output, $r_{t}=$ Nominal interest rate, $M_{t}=$ Nominal money balances. 
Table 3: Prior and Posterior distributions-Full sample

\begin{tabular}{|c|c|c|c|c|c|c|c|c|c|c|c|c|c|}
\hline & \multirow{3}{*}{ Description } & \multicolumn{6}{|c|}{$\mathcal{M}_{A}$} & \multicolumn{3}{|c|}{$\mathcal{M}_{B}$} & \multicolumn{3}{|c|}{$\mathcal{M}_{C}$} \\
\hline & & \multicolumn{3}{|c|}{ Prior distribution } & \multicolumn{3}{|c|}{$\underline{\text { Posterior distribution }}$} & \multicolumn{3}{|c|}{$\underline{\text { Posterior distribution }}$} & \multicolumn{3}{|c|}{$\underline{\text { Posterior distribution }}$} \\
\hline & & Distr. & Mean & Std.dev. & Mean & $5 \%$ & $95 \%$ & Mean & $5 \%$ & $95 \%$ & Mean & $5 \%$ & $95 \%$ \\
\hline$\lambda$ & Inverse labour elasticity & Gamma & 2 & 1 & 0.76 & 0.46 & 1.07 & 1.43 & 0.46 & 2.46 & 0.77 & 0.51 & 1.01 \\
\hline$\sigma$ & Inverse intertemporal elasticity & Gamma & 1.5 & 0.5 & 2.11 & 1.51 & 2.75 & 2.14 & 1.13 & 3.14 & 1.64 & 0.92 & 2.31 \\
\hline$h$ & Habit persistence & Beta & 0.7 & 0.1 & 0.88 & 0.82 & 0.93 & 0.66 & 0.51 & 0.80 & 0.88 & 0.79 & 0.95 \\
\hline$\xi$ & Calvo prices & Beta & 0.5 & 0.2 & 0.51 & 0.41 & 0.61 & 0.77 & 0.70 & 0.85 & 0.53 & 0.43 & 0.64 \\
\hline$d$ & Portfolio adjustment & Gamma & 2 & 1 & 1.33 & 0.34 & 2.57 & 0 & n.a. & n.a. & n.a. & n.a. & n.a. \\
\hline$\gamma$ & Inverse money demand elasticity & Gamma & 10 & 5 & 7.67 & 4.02 & 11.07 & 6.89 & 4.91 & 8.92 & n.a. & n.a. & n.a. \\
\hline$\alpha_{r}$ & Taylor rule smoothing & Beta & 0.5 & 0.2 & 0.27 & 0.13 & 0.41 & 0.24 & 0.07 & 0.40 & 0.21 & 0.10 & 0.32 \\
\hline$\alpha_{y}$ & Taylor rule output & Gamma & 0.125 & 0.125 & 0.11 & 0.03 & 0.18 & 0.21 & 0.05 & 0.38 & 0.08 & 0.00 & 0.15 \\
\hline$\alpha_{\pi}$ & Taylor rule inflation & Gamma & 1.5 & 0.5 & 2.17 & 1.55 & 2.74 & 1.13 & 0.62 & 1.61 & 2.30 & 1.69 & 2.91 \\
\hline$\alpha_{\mu}$ & Taylor rule money & Gamma & 0.125 & 0.125 & 0.52 & 0.31 & 0.71 & 1.30 & 0.89 & 1.68 & n.a. & n.a. & n.a. \\
\hline$\rho_{g}$ & Preference & Beta & 0.5 & 0.2 & 0.40 & 0.27 & 0.52 & 0.70 & 0.54 & 0.85 & 0.36 & 0.20 & 0.52 \\
\hline$\rho_{z}$ & Technology & Beta & 0.5 & 0.2 & 0.95 & 0.92 & 0.98 & 0.87 & 0.82 & 0.93 & 0.95 & 0.93 & 0.98 \\
\hline$\rho_{m}$ & Money demand & Beta & 0.5 & 0.2 & 0.92 & 0.88 & 0.96 & 0.94 & 0.92 & 0.96 & n.a. & n.a. & n.a. \\
\hline$\rho_{r}$ & Monetary policy & Beta & 0.5 & 0.2 & 0.75 & 0.68 & 0.82 & 0.70 & 0.57 & 0.84 & 0.83 & 0.76 & 0.90 \\
\hline$\sigma_{g}$ & Preference & InvGamma & 0.02 & $2^{*}$ & 0.15 & 0.11 & 0.19 & 0.06 & 0.05 & 0.07 & 0.13 & 0.04 & 0.19 \\
\hline$\sigma_{z}$ & Technology & InvGamma & 0.02 & $2^{*}$ & 0.02 & 0.01 & 0.03 & 0.12 & 0.04 & 0.23 & 0.016 & 0.01 & 0.02 \\
\hline$\sigma_{r}$ & Monetary policy & InvGamma & 0.02 & $2^{*}$ & 0.005 & 0.004 & 0.007 & 0.007 & 0.005 & 0.009 & 0.005 & 0.004 & 0.007 \\
\hline \multirow[t]{2}{*}{$\sigma_{m}$} & Money demand & InvGamma & 0.02 & $2^{*}$ & 0.28 & 0.19 & 0.38 & 0.14 & 0.12 & 0.15 & n.a. & n.a. & n.a. \\
\hline & Log marginal density & & & & & 3162.2 & & & 3137.5 & & & 2454.5 & \\
\hline
\end{tabular}

Notes. Posterior distributions are obtained using the Metropolis-Hastings algorithm with 250,000 draws after discarding the first 50,000 draws. For the Inverse

Gamma distribution the degrees of freedom are reported. In this Table $\psi$ is set equal to one. $\mathcal{M}_{A}$ is the model with a forward looking money demand and money in the policy rule. $\mathcal{M}_{B}$ is the model with a static money demand and money in the policy rule. $\mathcal{M}_{C}$ is a conventional money-less NK model that abstracts from money entirely. To test the stability of the posterior samples we use the methods described in Brooks and Gelman (1998). The Log marginal data density is computed using the modified harmonic mean estimator of Geweke (1999). Model favoured by the data attains the highest marginal data density. 
Table 4: Posterior distributions - Subsamples

\begin{tabular}{|c|c|c|c|c|c|c|c|c|c|c|c|c|c|}
\hline & \multirow{4}{*}{ Description } & \multicolumn{6}{|c|}{ Pre-1979 } & \multicolumn{6}{|c|}{ Post-1982 } \\
\hline & & \multicolumn{3}{|c|}{$\mathcal{M}_{A}$} & \multicolumn{3}{|c|}{$\mathcal{M}_{B}$} & \multicolumn{3}{|c|}{$\mathcal{M}_{A}$} & \multicolumn{3}{|c|}{$\mathcal{M}_{B}$} \\
\hline & & \multicolumn{3}{|c|}{$\underline{\text { Posterior distribution }}$} & \multicolumn{3}{|c|}{$\underline{\text { Posterior distribution }}$} & \multicolumn{3}{|c|}{$\underline{\text { Posterior distribution }}$} & \multicolumn{3}{|c|}{$\underline{\text { Posterior distribution }}$} \\
\hline & & Mean & $5 \%$ & $95 \%$ & Mean & $5 \%$ & $95 \%$ & Mean & $5 \%$ & $95 \%$ & Mean & $5 \%$ & $95 \%$ \\
\hline$\lambda$ & Inverse labour elasticity & 0.50 & 0.23 & 0.74 & 1.12 & 0.24 & 2.19 & 1.26 & 0.76 & 1.75 & 1.48 & 0.76 & 2.25 \\
\hline$\sigma$ & Inverse intertemporal elasticity & 1.94 & 1.24 & 2.63 & 1.26 & 0.63 & 1.82 & 2.54 & 1.76 & 3.28 & 1.97 & 1.17 & 2.74 \\
\hline$h$ & Habit persistence & 0.85 & 0.78 & 0.92 & 0.62 & 0.47 & 0.78 & 0.89 & 0.83 & 0.95 & 0.66 & 0.53 & 0.78 \\
\hline$\xi$ & Calvo prices & 0.46 & 0.34 & 0.57 & 0.70 & 0.59 & 0.80 & 0.32 & 0.21 & 0.42 & 0.32 & 0.18 & 0.48 \\
\hline$d$ & Portfolio adjustment & 1.18 & 0.23 & 2.31 & n.a. & n.a. & n.a. & 1.49 & 0.41 & 2.54 & n.a. & n.a. & n.a. \\
\hline$\gamma$ & Inverse money demand elasticity & 5.47 & 1.30 & 9.29 & 4.87 & 2.85 & 6.76 & 10.38 & 6.98 & 13.82 & 11.69 & 8.57 & 14.42 \\
\hline$\alpha_{r}$ & Taylor rule smoothing & 0.32 & 0.15 & 0.49 & 0.24 & 0.06 & 0.42 & 0.43 & 0.28 & 0.59 & 0.25 & 0.08 & 0.43 \\
\hline$\alpha_{y}$ & Taylor rule output & 0.11 & 0.03 & 0.18 & 0.19 & 0.05 & 0.31 & 0.18 & 0.05 & 0.30 & 0.18 & 0.07 & 0.29 \\
\hline$\alpha_{\pi}$ & Taylor rule inflation & 1.92 & 1.34 & 2.48 & 1.13 & 0.64 & 1.60 & 2.82 & 2.04 & 3.53 & 2.37 & 1.59 & 3.10 \\
\hline$\alpha_{\mu}$ & Taylor rule money & 0.65 & 0.32 & 0.93 & 1.25 & 0.84 & 1.67 & 0.34 & 0.16 & 0.51 & 0.60 & 0.39 & 0.84 \\
\hline$\rho_{g}$ & Preference & 0.42 & 0.26 & 0.58 & 0.68 & 0.47 & 0.87 & 0.49 & 0.35 & 0.63 & 0.83 & 0.75 & 0.93 \\
\hline$\rho_{z}$ & Technology & 0.96 & 0.93 & 0.99 & 0.89 & 0.83 & 0.96 & 0.95 & 0.93 & 0.98 & 0.94 & 0.90 & 0.98 \\
\hline$\rho_{m}$ & Money demand & 0.85 & 0.76 & 0.95 & 0.89 & 0.85 & 0.94 & 0.95 & 0.93 & 0.98 & 0.96 & 0.95 & 0.98 \\
\hline$\rho_{r}$ & Monetary policy & 0.70 & 0.60 & 0.80 & 0.72 & 0.60 & 0.83 & 0.67 & 0.57 & 0.77 & 0.53 & 0.41 & 0.66 \\
\hline$\sigma_{g}$ & Preference & 0.14 & 0.07 & 0.19 & 0.04 & 0.02 & 0.05 & 0.15 & 0.10 & 0.19 & 0.05 & 0.03 & 0.06 \\
\hline$\sigma_{z}$ & Technology & 0.02 & 0.01 & 0.03 & 0.07 & 0.02 & 0.13 & 0.014 & 0.010 & 0.02 & 0.017 & 0.01 & 0.02 \\
\hline$\sigma_{r}$ & Monetary policy & 0.005 & 0.003 & 0.006 & 0.006 & 0.004 & 0.008 & 0.004 & 0.003 & 0.005 & 0.005 & 0.003 & 0.006 \\
\hline$\sigma_{m}$ & Money demand & 0.50 & 0.17 & 1.02 & 0.13 & 0.11 & 0.15 & 0.16 & 0.12 & 0.20 & 0.10 & 0.09 & 0.12 \\
\hline & Log marginal density & & 1297.2 & & & 1279.6 & & & 1739.1 & & & 1728.2 & \\
\hline
\end{tabular}

$\overline{\text { Notes. Posterior distributions are obtained using the Metropolis-Hastings algorithm with 250,000 draws after discarding the first 50,000 draws. For the Inverse }}$ Gamma distribution the degrees of freedom are reported. In this Table $\psi$ is set equal to one. $\mathcal{M}_{A}$ is the model with a forward looking money demand and money in the policy rule. $\mathcal{M}_{B}$ is the model with a static money demand and money in the policy rule. To test the stability of the posterior samples we use the methods described in Brooks and Gelman (1998). The Log marginal data density is computed using the modified harmonic mean estimator described in Geweke (1999). Model favoured by the data attains the highest marginal data density. 